\title{
Inconsistencies in Data Requirements of EU Legislation Involving Tests on Animals
}

\author{
Kristina Wagner, Bettina Fach, and Roman Kolar
}

German Animal Welfare Federation / Animal Welfare Academy, Neubiberg, Germany

\begin{abstract}
Summary
European Union (EU) legislation on the protection of animals used for scientific purposes requires that alternative methods must be used instead of animal tests wherever they are available. Unfortunately, this provision is not implemented to its full extent when it comes to risk assessment of chemicals and new products prior to their authorization and placing on the market in the EU. In this study, we screened data requirements of relevant EU law regarding chemicals (REACH), biocides, pesticides, and food safety (Novel Food) and found that data requirements as part of the risk assessment do not always reflect stateof-the-art science and technology. Most of the data requirements we investigated still include testing on animals for many toxicological endpoints, even though more than 40 alternative testing methods accepted at the level of the EU or the OECD are available. This may be due to a multitude of reasons, including a shortage of both manpower to implement existing knowledge and expertise in the field of alternative methods, as well as unclear and misleading statements on the applicability and state of validation of alternative methods. In conclusion, we strongly suggest a homogeneous EU-wide approach for all areas involving risk assessment of substances with the goal of better implementing the 3Rs and complying with Directive 2010/63/EU. This also would streamline data requirements, save costs on various levels, and enhance product safety for consumers.
\end{abstract}

Keywords: animal welfare, 3Rs, alternative method, regulatory testing

\begin{tabular}{|c|c|c|c|}
\hline \multicolumn{4}{|c|}{ List of abbreviations } \\
\hline ADS & additional data set & LLNA & Local Lymph Node Assay \\
\hline ATP & Adaptation to Technical Progress & MAD & Mutual Acceptance of Data \\
\hline BPD & Biocidal Products Directive & MOA & Mode of Action \\
\hline BPR & Biocidal Products Regulation & NCBI & National Center for Biotechnology \\
\hline CDS & core data set & & Information \\
\hline DG & Directorate General & NIEHS & National Institute of Environmental Health \\
\hline $\mathrm{EC}$ & European Commission & & Sciences \\
\hline ECHA & European Chemicals Agency & OECD & Organisation for Economic Co-operation \\
\hline ECVAM & $\begin{array}{l}\text { European Centre for the Validation of } \\
\text { Alternative Methods }\end{array}$ & PPPR & $\begin{array}{l}\text { and Development } \\
\text { Plant Protection Products Regulation }\end{array}$ \\
\hline EFSA & European Food Safety Authority & QSAR & Quantitative Structure Activity Relationship \\
\hline EOGRTS & $\begin{array}{l}\text { Extended One-Generation Reproductive } \\
\text { Toxicity Study }\end{array}$ & REACH & $\begin{array}{l}\text { Registration, Evaluation, Authorisation and } \\
\text { Restriction of Chemicals }\end{array}$ \\
\hline EP & European Parliament & $\mathrm{SCF}$ & Scientific Committee on Food \\
\hline EPA & Environmental Protection Agency & SOP & Standard Operating Procedure \\
\hline ESAC & ECVAM scientific advisory committee & TFEU & $\begin{array}{l}\text { Treaty on the Functioning of } \\
\text { the European Union }\end{array}$ \\
\hline EU & European Union & TG & Test Guideline \\
\hline $\begin{array}{l}\text { GD } \\
\text { ICCVAM }\end{array}$ & $\begin{array}{l}\text { Guidance Document } \\
\text { Interagency Coordinating Committee on }\end{array}$ & TMR & Test Methods Regulation \\
\hline ICCVAM & $\begin{array}{l}\text { Interagency Coordinating Committee on } \\
\text { the Validation of Alternative Methods }\end{array}$ & TSAR & Tracking System for Alternative test methods \\
\hline IHCP & Institute for Health and Consumer Protection & & $\begin{array}{l}\text { Review, Validation and Approval in } \\
\text { the Context of EU Regulations on Chemicals }\end{array}$ \\
\hline JRC & Joint Research Centre & WOE & Weight of Evidence approach \\
\hline
\end{tabular}




\section{Introduction}

\subsection{Current situation}

As per the latest EU statistics published in the Sixth Report on the Statistics on the Number of Animals used for Experimental and other Scientific Purposes in the Member States of the European Union ${ }^{1}, 8.7 \%$ of a total of about 12 million animals were used for toxicological and other safety evaluations in 2008. This number is likely to rise in the coming years, given the ever increasing number of new products being developed and the significant increase in concern over the last decades regarding both hazards to human health and environmental pollution. This concern is also reflected in new testing requirements under the EU chemicals regulation, REACH (Hartung and Rovida, 2009).

Both the public and policy makers have focused huge efforts on moving the production and use of chemicals towards a "greener" chemistry. Environmental and consumer protection policies thus are based more and more on the precautionary principle, "the polluter pays" principle, and the substitution principle (sustainability). The toxicological profile of most chemicals in use is not yet fully known, even though toxicological and other safety evaluations have been required in the European Community since the late 1960s for chemicals among other substances, with the introduction of a 1967 European law covering dangerous substances. The law, known as the Dangerous Substances Directive ${ }^{2}$, introduced EU-wide provisions on the classification, packaging, and labeling of dangerous substances in order to protect public health, in particular the health of workers handling those substances. In addition, risk assessment or safety evaluation is required for biocidal products, plant protection products, food and feed, and pharmaceuticals. Along with the assessment of physico-chemical properties and eco-toxicological assessment, possible hazards and/or adverse effects caused by active substances or products must be evaluated. To this end, data requirements of the respective EU legislation specify several endpoints relevant to human health. So far, however, the good intention of better protecting humans, animals, and the environment has, in the past, resulted in more testing on animals, and it may do so in the future as well, unless all measures are taken to keep animal testing to a minimum.

\subsection{Problem}

It seems understood that any effort must be made to apply only the most up-to-date testing methods to ensure consumer and en- vironmental safety. Furthermore, it is now a common goal to reduce testing on animals to an absolute minimum and to protect them from distress and suffering.

However, reality does not reflect these considerations satisfactorily. Even though technical progress is fast, especially in the biosciences, and the number of alternative methods being developed and accepted is constantly increasing, the lion's share of risk assessment is still based on animal testing. Most of the existing in vivo methods are inhumane, derive from the last century, and result in doubtful safety estimates, as it cannot be assumed that results from these methods can be reliably transferred to humans. Despite this, as more safety evaluations are required the number of tests on animals will surely rise.

This is hard to accept - and not only because it means that consumer safety may be at risk. It also points to contradictory provisions within the EU. These provisions clearly mandate the protection of animals and the consideration of animal welfare in formulating and implementing the Union's policies concerning agriculture, fisheries, transport, internal market, research and technological development, and space. They include the Treaty on the Functioning of the European Union (TFEU), amended in 2009, both the former and the current Directives on the protection of animals used for scientific purposes ${ }^{3,4}$, the European Convention ETS $123^{5}$, and the Animal Welfare Acts of EU Member States. Provisions to protect animals used for scientific purposes all share common principles, to wit: each experiment must be essential for a given purpose; the number of animals must be reduced to a minimum; pain, suffering, and harm also must be reduced to a minimum; and pain, suffering and harm caused to the animals must be ethically justifiable (Kolar, 2006). This means that whatever method of obtaining scientifically satisfactory results that does not use animals or uses fewer animals, should be employed. The criticism is frequently raised that these provisions are not fully implemented (Schiffelers et al., 2007).

\subsection{Project}

Our analysis of existing data requirements of relevant EU legislation requiring testing on animals prior to authorization and placing on the market of chemicals, active substances, and finished products (biocidal products, plant protection products, Novel Food) is aimed at effecting replacement and reduction of toxicity tests on animals. We know of no other such study in which data requirements of relevant EU legislation were analyzed as comprehensively, and in synopsis, regarding consistency and state-of-the-art of the implementation of the 3Rs. We

\footnotetext{
1 European Commission (2010). Sixth Report on the Statistics on the Number of Animals used for Experimental and other Scientific Purposes in the Member States of the European Union (COM (2010) 511)

2 Council Directive 67/548/EEC of 27 June 1967 on the approximation of laws, regulations and administrative provisions relating to the classification, packaging and labelling of dangerous substances

3 Council of the European Union (1986). Council Directive 86/609/EEC of 24 November 1986 on the approximation of laws, regulations and administrative provisions of the Member States regarding the protection of animals used for experimental and other scientific purposes

4 European Union (2010). Directive 2010/63/EU of the European Parliament and of the Council of 22 September 2010 on the protection of animals used for scientific purposes

5 Council of Europe (1986). European Treaty Series - No. 123: European Convention for the Protection of Vertebrate Animals used for Experimental and Other Scientific Purposes, 1986. Text amended according to the provisions of the Protocol (ETS No. 170) as of its entry into force on 2 December 2005.
} 
give a detailed analysis of shortcomings of individual EU legislation and also compare the legislations. To help reduce the number of tests on animals for safety evaluations and to provide for the best possible protection of humans, animals, and the environment, we suggest a homogenous approach that provides guidance on how to structure data requirements. This approach, along with a conclusion of our analysis of existing data requirements, will be presented to the European Commission (EC). We hope to encourage the $\mathrm{EC}$ to act immediately to eliminate from data requirements those animal tests that can be replaced by $3 \mathrm{Rs}$ methods and to consider our suggestions for improvement.

\section{Possibilities to replace, reduce, and refine animal testing}

\subsection{Accepted 3Rs Methods}

According to the 3Rs principle introduced by Russell and Burch (Russell and Burch, 1959), such a method could either be one that does not involve (live) animals, or one that significantly reduces the number of animals used, or a method that is improved by reducing suffering, pain, and distress inflicted on the animals.

In basic and medical research, there are no formal requirements for research methods. An alternative is established when many people start using it as a standard method, even though it might take some time and high-profile publications or workshops to spread the information. In contrast, validation and regulatory acceptance is a major issue in regulatory toxicology. Regulatory acceptance is the formal adoption of a validated test method by a regulatory agency or authority. Problems of regulatory acceptance of 3Rs methods include long lag periods (up to 11 years, ECVAM, 2005) and sometimes unrealistic demands: Most animal test methods have not been formally validated and their results have never been proven to be relevant to human health or consumer safety. However, regulatory toxicity usually demands that an alternative method must achieve the same results as an animal test to be accepted as a stand-alone replacement, even though the alternative method may follow a completely different scientific approach. And finally, acceptance of an alternative method by one authority does not mean it will be accepted universally, as regulatory acceptance practices may differ from country to country and even among competent authorities within a particular country.

Principles and criteria for the validation process and regulatory acceptance of new or revised toxicological test methods have been developed by several agencies and organizations: Most importantly, the Organisation for Economic Co-operation and Development (OECD) issued a Guidance Document (GD) on the Validation and International Acceptance of New or Updated Test Methods for Hazard Assessment (OECD, 2005). Because the OECD also encourages worldwide mutual acceptance of data (MAD), methods adopted as an OECD Test Guideline are widely accepted and used internationally in the 34 (to date) OECD member states and by global partners like Brazil, China, and India. Validated test methods can be submitted to the OECD for formal adoption as an OECD Test Guideline (TG). According to the OECD, formal validation, as described in the OECD GD, "contributes strongly to the international acceptance of any proposed test method." However, "validation is not a requirement" for the development of a method as a TG (OECD, 2005). The OECD seeks to promote the "harmonization of international regulatory acceptance of adequately validated test methods" (OECD, 2005) and provides guidance on international regulatory acceptance for its member countries.

For our study, the activities of the European Centre for the Validation of Alternative Methods (ECVAM) were of great interest. ECVAM has coordinated the validation of alternative approaches in the EU since 1991, and with the provisions laid down in Article 48 and Annex VII of Directive 2010/63/EU, it will now also become the Union Reference Laboratory for the validation of alternative methods. At present, it provides guidance on regulatory acceptance through its workshops and publications for the EU and also participates in the drafting of test guidelines for the EU or OECD when requested. ECVAM provides scientific and technical advice to Commission Services, like Directorate General (DG) Environment, DG Enterprise, DG Health and Consumer Protection, and DG Research, and it also undertakes projects with relevance to validation activities. ECVAM also ensures publication of validation studies, provides access to the test method protocols and standard operating procedures (SOPs), and seeks to facilitate the adoption of validated methods by including the OECD acceptance principles and criteria as part of its test method review. After a new method has been submitted to ECVAM, it is assessed for its robustness, reliability, and predictive capacity. Validation study reports are also subjected to independent peer review, supported by the ECVAM scientific advisory committee (ES$A C)$. ESAC issues an ESAC statement on the validity of a new test method which then is communicated by the Chemical Substances Unit of the EC's Environment DG to other Commission Services and to other organizations such as the EU Competent Authorities, OECD, and ICCVAM. The Commission Services may accept and/or endorse an ESAC statement, suggest further study, or request clarification (Worth and Balls, 2001). Discussions with EU authorities who make the acceptance decision are coordinated by the Commission Services. ESAC members disseminate the information to regulatory authorities in their respective countries.

We considered alternative methods relevant for testing of chemicals, active substances, and finished products (except pharmaceutical products) that are either regulatory accepted by the OECD or validated by ECVAM. For an overview of the test methods we considered, see Table 1 .

\subsection{Other tools considered in analyzed EU legislation}

Apart from using testing methods that do not involve (live) animals or that reduce the numbers of animals or refine an in vivo method to reduce pain and/or distress, there are several "nontesting" means to avoid testing on animals. 
Tab. 1: Alternative test methods with regulatory acceptance

Adopted with modifications from AltTox's table of "Validated/Accepted Alternative Methods" that can be found at: http://alttox.org/ttrc/validation-ra/validated-ra-methods.html

\begin{tabular}{|c|c|c|c|}
\hline Endpoint & Method Name & Test Type & $\begin{array}{l}\text { International Regulatory } \\
\text { Acceptance }\end{array}$ \\
\hline Acute aquatic toxicity & Upper threshold concentration step-down approach & In vivo & OECD GD 126 (2010) \\
\hline \multirow{5}{*}{$\begin{array}{l}\text { Acute mammalian toxicity } \\
\text { (oral) }\end{array}$} & Acute toxic class method & In vivo & OECD TG 423 (2001) \\
\hline & Fixed dose procedure & In vivo & OECD TG 420 (2001) \\
\hline & Up-and-down procedure & In vivo & OECD TG 425 (2006) \\
\hline & $\begin{array}{l}\text { Normal human keratinocyte neutral red uptake } \\
\text { (NHK NRU) assay }\end{array}$ & In vitro & OECD GD 129 (2010) \\
\hline & Balb/c 3T3 neutral red uptake assay & In vitro & OECD GD 129 (2010) \\
\hline \multirow{2}{*}{$\begin{array}{l}\text { Acute mammalian toxicity } \\
\text { (inhalation) }\end{array}$} & Acute toxic class method & In vivo & OECD TG 436 (2009) \\
\hline & Fixed concentration procedure & In vivo & Draft TG OECD 433 \\
\hline Dermal penetration & In vitro skin absorption methods & In vitro & $\begin{array}{l}\text { OECD TG } 428(2004) \\
\text { OECD GD } 28(2004)\end{array}$ \\
\hline \multirow[t]{2}{*}{ Endocrine-mediated toxicity } & $\begin{array}{l}\text { Estrogen receptor (ER)-alpha transcriptional } \\
\text { activation assay for estrogen agonists (STTA) }\end{array}$ & In vitro & OECD TG 455 (2009) \\
\hline & H295R steroidogenesis assay & In vitro & OECD TG 456 (2011) \\
\hline \multirow[t]{2}{*}{ Eye corrosion } & Bovine corneal opacity permeability (BCOP) test & Ex vivo & OECD TG 437 (2009) \\
\hline & Isolated chicken eye (ICE) test & Ex vivo & OECD TG 438 (2009) \\
\hline \multirow[t]{8}{*}{ Genotoxicity } & Bacterial reverse mutation (Ames) test & In vitro & OECD TG 471 (1997) \\
\hline & In vitro cell gene mutation test & In vitro & OECD TG 476 (1997) \\
\hline & In vitro chromosomal aberration test & In vitro & OECD TG 473 (1997) \\
\hline & In vitro mammalian cell micronucleus test & In vitro & OECD TG 487 (2010) \\
\hline & In vitro sister chromatid exchange test & In vitro & OECD TG 479 (1986) \\
\hline & In vitro unscheduled DNA synthesis test & In vitro & OECD TG 482 (1986) \\
\hline & Saccharomyces cerevisiae gene mutation assay & In vitro & OECD TG 480 (1986) \\
\hline & Saccharomyces cerevisiae mitotic recombination assay & In vitro & OECD TG 481 (1986) \\
\hline \multirow[t]{4}{*}{$\begin{array}{l}\text { Immunotoxicity/ } \\
\text { Skin Sensitization }\end{array}$} & Local lymph node assay (LLNA) & In vivo & $\begin{array}{l}\text { OECD TG } 429 \text { (2002); } \\
\text { updated OECD } \\
\text { TG } 429(2010)\end{array}$ \\
\hline & Reduced LLNA: rLLNA & In vivo & $\begin{array}{l}\text { Updated OECD } \\
\text { TG } 429(2010)\end{array}$ \\
\hline & Nonradiolabelled LLNA: DA & In vivo & OECD TG 442A (2010) \\
\hline & Nonradiolabelled LLNA: BrdU-ELISA & In vivo & OECD TG 442B (2010) \\
\hline \multirow[t]{2}{*}{ Phototoxicity } & 3T3 Neutral Red Uptake Phototoxicity Test & In vitro & OECD TG 432 (2004) \\
\hline & $\begin{array}{l}\text { 3T3 NRU Phototoxicity Test: } \\
\text { Application to UV filter chemicals }\end{array}$ & In vitro & OECD TG 432 (2004) \\
\hline $\begin{array}{l}\text { Reproductive \& } \\
\text { developmental toxicity }\end{array}$ & Extended one-generation reproductive toxicity study & In vivo & OECD TG 443 (2011) \\
\hline \multirow[t]{3}{*}{ Skin corrosion } & EST-1000 human reconstructed epidermis & In vitro & $\begin{array}{l}\text { OECD TG } 431(2004) \text {; } \\
\text { draft updated } \\
\text { TG } 431(2009)\end{array}$ \\
\hline & Corrositex ${ }^{\circledR}$ noncellular membrane & In vitro & OECD TG 435 (2006) \\
\hline & EpiSkin ${ }^{\circledR}$ human skin model & In vitro & $\begin{array}{l}\text { OECD TG } 431 \text { (2004); } \\
\text { draft updated } \\
\text { TG } 431 \text { (2009) }\end{array}$ \\
\hline
\end{tabular}




\begin{tabular}{|c|c|c|c|}
\hline Endpoint & Method Name & Test Type & $\begin{array}{l}\text { International Regulatory } \\
\text { Acceptance }\end{array}$ \\
\hline \multirow[t]{4}{*}{ Skin corrosion (cont.) } & EpiDermTM human skin model & In vitro & $\begin{array}{l}\text { OECD TG } 431(2004) \text {; } \\
\text { draft updated } \\
\text { TG } 431(2009)\end{array}$ \\
\hline & $\begin{array}{l}\text { Rat skin transcutaneous electrical resistance } \\
\text { (TER) assay }\end{array}$ & Ex vivo & $\begin{array}{l}\text { OECD TG } 430(2004) ; \\
\text { draft updated } \\
\text { TG } 430(2009)\end{array}$ \\
\hline & SkinEthic ${ }^{T M}$ human skin model & In vitro & $\begin{array}{l}\text { OECD TG } 431(2004) \\
\text { draft updated } \\
\text { TG } 431 \text { (2009) }\end{array}$ \\
\hline & Vitrolife-Skin human reconstructed epidermis & In vitro & $\begin{array}{l}\text { OECD TG } 431 \text { (2004); } \\
\text { draft updated } \\
\text { TG } 431 \text { (2009) }\end{array}$ \\
\hline \multirow[t]{3}{*}{ Skin irritation } & EpiSkin ${ }^{\circledR}$ skin irritation test (with MTT reduction) & In vitro & OECD TG 439 (2010) \\
\hline & EpiDermTM SIT model (EPI-200) & In vitro & OECD TG 439 (2010) \\
\hline & SkinEthic RHE model & In vitro & OECD TG 439 (2010) \\
\hline
\end{tabular}

QSAR, read-across

These include computational methods like the Quantitative Structure Activity Relationship (QSAR), which seeks to predict intrinsic properties of chemicals by using various databases or theoretical models to quantitatively relate characteristics of a chemical to a measure of particular activity. In addition, substances can also be grouped into chemical categories or groups depending on observations suggesting that their physico-chemical and human health and/or eco-toxicological properties and/ or environmental fate properties are likely to show similarities or follow a regular pattern. The "read-across" approach can be used to assess physico-chemical properties, toxicity, environmental fate, and eco-toxicity of a chemical by interpolation of endpoint information within a group of chemicals from one (the source chemical) to another (the target chemical). This is usually done on the basis of structural similarity or on the basis of the same mode or mechanism of action (MOA).

\section{Waiving, rules for adaptation of data requirements}

Waiving of animal tests according to special waiving criteria also can help to reduce testing on animals if, for example, testing is technically not possible because the substance is flammable in air at room temperature. Testing may also be omitted if the available information indicates that the substance is highly toxic. Other examples include omitting testing for skin or eye irritation if the criteria are met for classification of the substance as corrosive to the skin or irritating to the eyes, as in REACH or the Biocidal Products Regulation (BPR). In some cases it may not be necessary to assess certain endpoints because the related exposure route is unlikely, e.g., if the substance is unlikely to come in contact with aquatic organisms because it is only used in closed circuits and not released into the environment. In such cases, tests to assess possible aquatic toxicity of a substance can be waived. Criteria such as those mentioned above can be included in the rules for adaptation of data requirements for all toxicological endpoints that involve testing on animals so that a certain animal test does not have to be performed. The rules for adaptation also can encourage applicants to combine several endpoints in long-term toxicity studies, so reducing the numbers of animals used.

\section{Evaluation of available data}

The available data on a chemical or substance, especially historical human data (e.g., clinical data) and data from in vitro and in vivo studies that have already been performed also can be considered. They may be used in a Weight of Evidence approach (WOE). In this approach, sufficient information from several independent sources is used, leading to the assumption/ conclusion that a substance has (or has not) a particular dangerous property, while the information from each single source alone is regarded as insufficient to support this notion.

These non-testing means can be convenient tools to reduce the number of animals used for a specific endpoint or to refine animal testing by integrating them into a tiered or integrated testing strategy or by designing substance-tailored, exposuredriven testing.

\section{Analyzed EU legislation and data requirements}

\subsection{Test Methods Regulation (EC) No. 440/2008}

The Test Methods Regulation (TMR), Regulation (EC) No. $440 / 2008^{6}$, replaced Annex V of the Dangerous Substances Di-

\footnotetext{
6 European Commission (2008). Council Regulation (EC) No. 440/2008 of 30 May 2008 laying down test methods pursuant to Regulation (EC) No 1907/2006 of the European Parliament and of the Council on the Registration, Evaluation, Authorisation and Restriction of Chemicals (REACH)
} 
rective 67/548/EEC in 2008. It lays down the legally binding EU standard test methods to determine the hazardous properties of chemicals. Applicants for authorization of a substance are required to use these test methods to fulfill data requirements for the EU chemicals regulation $\mathrm{REACH}^{7}$ and for the upcoming EU Regulation on Biocidal Products ${ }^{8}$. The data requirements for the EU Plant Protection Products Regulation (PPPR $)^{9}$ defined in the Annexes to Regulations (EU) No. 544/2011 ${ }^{10}$ and (EU) No. 545/2011 ${ }^{11}$, as well as several GDs for safety testing to comply with the EU Cosmetics Directive ${ }^{12}$, also refer to the test methods contained in the TMR.

The Annex to Regulation (EC) No. 440/2008 is divided into three parts (Part A, B, and C). In Part A, methods for the determination of physico-chemical properties of substances are laid down (e.g., boiling temperature, flammability, and explosive properties). As these do not involve in vivo testing, we did not consider this section in our analysis. Part B contains methods for the determination of effects on human health (e.g., acute or chronic toxicity, skin sensitization, eye irritation, carcinogenicity). This section was of major interest to our analysis as it contains in vitro and in vivo methods. Part $\mathrm{C}$ contains methods for assessment of environmental effects, eco-toxicity, and environmental fate (e.g., toxicity to fish, daphnia, or algae, bioconcentration, bio-degradability, etc.). Here, only the testing methods involving vertebrate animals (fish) were considered in our analysis.

In theory, the test methods in the Annex to the TMR are regularly updated, or new methods are introduced as required using the Adaptation to Technical Progress (ATP) procedure of the Regulation. Although all the technical work to prepare the new or updated methods is done by the Institute for Health and Consumer Protection (IHCP), the procedure for the ATP can be initiated only by the Chemicals Unit of DG Environment and the REACH Unit of DG Enterprise and Industry, which are the Commission DGs responsible for policy in this area (Tracking System for Alternative test methods Review, Validation and Approval in the Context of EU Regulations on Chemicals (TSAR) website $^{13}$, last date of access 20 March, 2012).

\subsection{REACH (Regulation (EC) No. 1907/2006)}

The EU Chemicals Regulation (EC) No. 1907/2006, REACH, deals with the Registration, Evaluation, Authorisation and Restriction of Chemical substances in the EU and entered into force on June 1, 2007.

In the Regulation, three major deadlines for registration of chemicals are set, determined by the tonnage in which a chemical is manufactured or imported. Accordingly, substances manufactured in amounts up to 1,000 tons per year are required to be registered by December 1, 2010, in amounts up to 100 tons per year by June 1, 2013, and up to 1 ton per year by June 1 , 2018. Chemicals of higher concern or toxicity also had to meet the 2010 deadline. Substances that are not registered by the respective deadline cannot be legally manufactured, imported, or used within the EU afterwards. The deadline for pre-registration of substances that were intended to be fully registered at a later date ended on December 1, 2008. About 143,000 chemical substances marketed in the EU were pre-registered by this time ${ }^{14}$. Although pre-registering was not mandatory, it is supposed to allow potential registrants much more time before they have to fully register.

$\mathrm{REACH}$ is intended to improve the protection of human health and the environment through better and earlier characterization of chemicals and their potential adverse effects. For decades, a large number of substances have been manufactured and placed on the market in Europe despite insufficient existing information on the hazards they pose to human health and the environment. REACH requires manufacturers and distributors to register their products and to prove that their product is safe enough to be used and that possible risks can be managed. The Regulation also calls for the progressive substitution of the most dangerous chemicals (phase-out) when suitable alternates have been identified.

\subsection{Biocidal Products Regulation}

The EU provisions concerning the placing on the market of biocidal products are currently set out in Directive 98/8/EC (Biocidal Products Directive, BPD) ${ }^{15}$. On June 12, 2009, the

\footnotetext{
7 European Commission (2006). Regulation (EC) No. 1907/2006 of the European Parliament and of the Council of 18 December 2006 concerning the Registration, Evaluation, Authorisation and Restriction of Chemicals (REACH), establishing a European Chemicals Agency, amending Directive 1999/45/EC and repealing Council Regulation (EEC) No. 793/93 and Commission Regulation (EC) No. 1488/94 as well as Council Directive 76/769/EEC and Commission Directives 91/155/EEC, 93/67/EEC, 93/105/EC and 2000/21/EC

8 European Commission (2009). Proposal for a Regulation of the European Parliament and of the Council concerning the placing on the market and use of biocidal products (COM(2009)267)

9 Regulation (EC) No. 1107/2009 of the European Parliament and of the Council of 21 October 2009 concerning the placing of plant protection products on the market and repealing Council Directives 79/117/EEC and 91/414/EEC

10 Commission Regulation (EU) No. 544/2011 of 10 June 2011 implementing Regulation (EC) No. 1107/2009 of the European Parliament and of the Council as regards the data requirements for active substances

11 Commission Regulation (EU) No. 545/2011 of 10 June 2011 implementing Regulation (EC) No. 1107/2009 of the European Parliament and of the Council as regards the data requirements for plant protection products

12 Council Directive 76/768/EEC of 27 July 1976 on the approximation of the laws of the Member States relating to cosmetic products

$13 \mathrm{http}: / /$ tsar.jrc.ec.europa.eu/

14 http://ec.europa.eu/enterprise/magazine/articles/industrial-policy/article_9312_en.htm

15 European Parliament and Council (1998). Directive 98/8/EC of the European Parliament and of the Council of 16 February 1998 concerning the placing of biocidal products on the market
} 
Commission published a proposal for a Biocidal Products Regulation (BPR) ${ }^{16}$ on the basis of a report on the functioning and implementation of Directive 98/8/EC. The objective of this proposal was to improve the functioning of the internal market in biocidal products while maintaining the high level of environmental and human health protection. The proposal builds on the principles laid down in Directive 98/8/EC, in particular the two-tier authorization process: first, the inclusion of the active substance in Annex I, and second, the authorization of the biocidal product. The proposed regulation is scheduled to enter into force on January 1, 2013. From 2013, coinciding with the coming-into-force of the BPR, the European Chemicals Agency (ECHA) will take over the biocides program from the biocides group within the IHCP.

The proposed Regulation, once adopted, will repeal and replace the current Directive. In order for the text to become law, the European Parliament (EP) and the Council of the EU, i.e., representatives of EU Member States, had to reach an agreement on the Commission's proposal in the Co-Decision Procedure. The EP voted and reached agreement on its position in the first reading on September 22, 2010 and passed it on to the Council, which officially adopted its position at the first reading on June 21, 2011. The Commission Communication on the Council position at the first reading was adopted on August 11, 2011. Subsequently, the EP's Environment Committee issued its report for the second reading in October 2011, which was followed by a second reading in the plenary session that started in January 2012. The BPR was adopted by the Council on May 22, 2012.

For our analysis, we considered the EC's proposal (COM(2009)267), the Council's official position at first reading ${ }^{17}$, and the EP's report for the second reading ${ }^{18}$. As the final text of the BPR was not determined at that time, we mainly wanted to investigate whether available accepted alternatives were considered in the legislative process.

\subsection{Plant Protection Products Regulation}

The EU supervises the sale and use of plant protection products, or pesticides, and sets standards to monitor and control pesticide residues. Plant protection products may act by disorienting insects or making crops less palatable for "pests", or they may act by killing insects, weeds, and fungi that are thought to be harmful. Such pesticides could have severe undesirable effects. Therefore, no plant protection product can be used in the EU un- less it first has been scientifically established to have no harmful effects on consumers, farmers, local residents, and passers-by, that it does not cause unacceptable effects on the environment, and that it is sufficiently effective against pests.

The evaluation, marketing, and use of pesticides in plant protection in the Community formerly were regulated under Council Directive 91/414/EEC ${ }^{19}$. A new legislative framework on pesticides based on a Commission proposal was adopted in 2009 by the EP and the Council that consists of Regulation (EC) No. 1107/2009 on placing on the market of plant protection products. The Regulation is intended to ensure a high level of protection for human and animal health and the environment by specifying strict criteria for approval of substances. In particular, this Regulation provides that carcinogens, mutagens, substances that may cause endocrine-mediated toxicity, substances toxic for reproduction or which are very persistent will not be approved unless exposure to humans is negligible. It also establishes a mechanism for the substitution of more toxic pesticides by safer (including non-chemical) alternatives. The legislative framework on pesticides also includes a Directive on the sustainable use of pesticides ${ }^{20}$, which aims at reducing the risk linked to the use of pesticides, improving the quality and efficacy of pesticide application equipment, ensuring better training and education of users, and developing integrated pest management schemes.

Data requirements for Regulation (EC) No. 1107/2009 are laid down in Regulation (EU) No. 544/2011 for active substances and Regulation (EU) No. 545/2011 for plant protection products. Since the end of 2003, the European Food Safety Authority (EFSA) deals with risk assessment issues, and the EC is responsible for the risk management decision. ${ }^{21}$

\subsection{Novel Foods Regulation}

According to the European Novel Foods legislation, Regulation (EC) No. 258/9722, foods and food ingredients that have not been used for human consumption to a significant degree in the EU before May 15, 1997 are defined as "Novel Foods" and "Novel Food ingredients" and must be authorized. In 2008 the EP, EC, and Council of the EU began talks to revise the regulation because essential elements needed to be discussed and resolved. The Commission presented a proposal for a new regulation $(\operatorname{COM}(2007)$ 872). However, the revision came to a standstill on March 28, 2011 when the three institutions failed

\footnotetext{
16 European Commission (2009). Proposal for a Regulation of the European Parliament and of the Council concerning the placing on the market and use of biocidal products, $\operatorname{COM}(2009) 267$

17 Position of the Council at first reading with a view to the adoption of a Regulation of the European Parliament and of the Council concerning the making available on the market and use of biocidal products - Adopted by the Council on 21 June 2011, 5032/2/11

18 Recommendation for Second Reading on the Council position at first reading with a view to the adoption of a regulation of the European Parliament and of the Council concerning the making available on the market and use of biocidal products (05032/2/2011 - C7-0251/2011 - 2009/0076(COD)), A7-0336/2011

19 Council Directive 91/414/EEC of 15 July 1991 concerning the placing of plant protection products on the market

20 Directive 2009/128/EC of the European Parliament and of the Council of 21 October 2009 establishing a framework for Community action to achieve the sustainable use of pesticides

21 http://ec.europa.eu/food/plant/plant_protection_products/approval_active_substances/index_en.htm

22 Regulation (EC) No. 258/97 of the European Parliament and of the Council of 27 January 1997 concerning novel foods and novel food ingredients
} 
to reach agreement at a final conciliation meeting on the issue of cloning. It has been unclear if and how the institutions will move forward on a revision of the regulation. Therefore, the existing Regulation (EC) No. 258/97 remains in place.

According to provisions laid down in Regulation (EC) No. $258 / 97$, companies that wish to submit an application for authorization must prove that the foods and food ingredients manufactured or distributed by them do not present a danger to the consumer, are not labelled to mislead the consumer, or differ from foods or food ingredients they are intended to replace to such an extent that their normal consumption would be nutritionally disadvantageous for the consumer. As proof, companies have to present a scientific information and safety assessment report with results from the risk assessment of the Novel Foods and Novel Food ingredients. A company is expected to consult the GD compiled by the $\mathrm{EC}^{23}$, which highlights the scientific information and the safety assessment report required in each case. However, the Novel Foods Regulation or the GD does not specify how risk assessment of Novel Foods or Novel Food ingredients should be designed or which testing methods should be used.

The scientific aspects of information necessary to support applications for placing on the European market Novel Foods and Novel Food ingredients were addressed by recommendations of the Scientific Committee on Food (SCF) until the EFSA took over the tasks of the SCF in 2003. Considering the significant development of such emerging sciences as nanotechnology and the proposed introduction of the assessment of traditional foods from non-EU countries on the basis of a history of safe use, EFSA will be asked by the EC to provide scientific and technical guidance for applicants in their preparation and presentation of the application for Novel Food and Novel Food ingredients.

\section{Work stages}

In our project we compared and analyzed data requirements of EU legislation involving animal testing for risk assessment of chemicals, active substances, and finished products (biocidal products, plant protection products) and for food safety (Novel Foods) in order to identify those endpoints where animal testing is still required even though an accepted alternative method is available. We also aimed to compare the structure of data requirements and to determine if they include rules for adaptation or reference to measures to avoid testing on animals, such as exposure-based waiving or a tiered testing approach. Based on our results, we aimed to identify essential steps that should be considered when designing future data requirements.

\subsection{Online and literature research}

We performed online and literature research to analyze the state-of-the-art in regulatory testing and alternative methods and existing studies on regulatory animal testing, integrated testing strategies, and the state-of-the-art in alternative methods that can be used for regulatory toxicity testing. We performed online searches via the US National Center for Biotechnology Information's (NCBI) database, PubMed ${ }^{24}$ with the search terms "integrated testing strategy," "tiered testing," "regulatory testing," AND "alternative method," "toxicology" AND "alternative method" and "toxicology" AND "testing strategy."

To obtain access to relevant scientific literature we used the OPACplus database (access is locally provided by the Bavarian State Library in Munich) and we searched for scientific literature via our own access to the German National Licenses Literature Database (Deutsche Nationallizenzen, via Deutsche Forschungsgemeinschaft, DFG).

We then proceeded to provide an overview of alternative methods that are already available and internationally accepted (accepted by the OECD and/or validated by ECVAM). We consulted the current OECD Guidelines for the Testing of Chemicals that can be found online in the OECD iLibrary ${ }^{25}$, the references to ECVAM validated/regulatory accepted alternative methods on ECVAM's website ${ }^{26}$, the Tracking System for Alternative test methods Review, Validation and Approval in the Context of EU Regulations on Chemicals (TSAR) that is provided online by the IHCP of the European Commission's Joint Research Centre (JRC), and the information that can be found online on the ICCVAM website of the U.S.- based National Institute of Environmental Health Sciences (NIEHS) ${ }^{27}$.

\subsection{Analysis of EU legislation and data requirements}

Texts of relevant EU legislation involving testing on animals for risk assessment of chemicals, active substances, and finished products were obtained via the EUR-Lex database of European Union law ${ }^{28}$. We checked related data requirements in terms of inclusion of already available and accepted alternative methods. We also examined and compared data requirements in terms of their structure and possible inclusion or reference to rules for adaptation, advice on possible measures to avoid testing on animals, and/or integrated testing strategies in order to waive or avoid testing on animals. We identified toxicological endpoints required to assess possible risks for human health for which (internationally) accepted or at least validated alternative methods are available. We then checked for each piece of legislation if these alternatives had already been taken into account.

\footnotetext{
23 Commission Recommendation of 29 July 1997 concerning the scientific aspects and the presentation of information necessary to support applications for the placing on the market of novel foods and novel food ingredients and the preparation of initial assessment reports under Regulation (EC) No 258/97 of the European Parliament and of the Council

24 http://www.ncbi.nlm.nih.gov/pubmed

25 http://www.oecd-ilibrary.org/content/package/chem_guide_pkg-en

26 http://ecvam.jrc.ec.europa.eu/

27 http://iccvam.niehs.nih.gov

28 http://eur-lex.europa.eu/en/index.htm
} 


\subsection{Data evaluation}

We documented lack of inclusion and the need to update data requirements (where animal tests are still required even though an alternative is already available). This analysis resulted in an overview of relevant EU legislation that compares the state of inclusion of alternative methods for each endpoint. We therefore identified central steps that we propose for consideration in the drafting process. In addition, it should be made standard procedure to adapt data requirements wherever possible by combination of endpoints, e.g., in long term and developmental toxicity studies, to reduce numbers of animals used in testing.

\section{Results}

\subsection{Test Methods Regulation, Regulation (EC) No. 440/2008}

Regulation (EC) No. 440/2008 includes clear statements on the importance of the $3 \mathrm{Rs}$, as does REACH when referring to the TMR. In Recital (5), Regulation (EC) No. 440/2008 states that: "The principles of replacement, reduction and refinement of the use of animals in procedures should be fully taken into account in the design of the test methods, in particular when appropriate validated methods become available to replace, reduce or refine animal testing." and in its Article 2: "The Commission shall review, where appropriate, the test methods contained in this Regulation with a view to replacing, reducing or refining testing on vertebrate animals."

\subsubsection{Rules for Adaptation to Technical Progress and importance to reduce testing on animals}

Adaptation to Technical Progress is carried out by separate Regulations to amend Regulation (EC) No. 440/2008. As described in 3.1, all the technical work to prepare new or updated methods is done by the EC's IHCP and the procedure for the Adaptation to Technical Progress can only be initiated by DG
Environment - Chemicals Unit and DG Enterprise and Industry - REACH Unit. In REACH, Recital 47, it is stated that: "In accordance with Directive 86/609/EEC, it is necessary to replace, reduce or refine testing on vertebrate animals. Implementation of this Regulation should be based on the use of alternative test methods, suitable for the assessment of health and environmental hazards of chemicals, wherever possible. The use of animals should be avoided by recourse to alternative methods validated by the Commission or international bodies, or recognised by the Commission or the Agency as appropriate to meet the information requirements under this Regulation. To this end, the Commission, following consultation with relevant stakeholders, should propose to amend the future Commission Regulation on test methods or this Regulation, where appropriate, to replace, reduce or refine animal testing. The Commission and the Agency should ensure that reduction of animal testing is a key consideration in the development and maintenance of guidance for stakeholders and in the Agency's own procedures."

However, in contrast to the above mentioned principles, according to which the implementation of REACH should be based on the use of alternative test methods wherever possible and on the goal of amending the TMR or REACH, where appropriate, to replace, reduce, or refine animal testing, we identified several issues concerning consistency, clarity of information, and Adaptation to Technical Progress that are not in line with the intentions of both REACH and the TMR.

Regarding Adaptation to Technical Progress, we found that even though newly adopted OECD TGs for in vitro skin irritation and eye irritation were already introduced via the above mentioned amending regulations, Regulation (EC) No. 440/2008 still contains outdated methods that should be deleted from the register. We also found that the Regulation fails to include newly accepted and already existing accepted alternative methods and reference to existing OECD GDs. Table 2 gives an overview of our findings regarding the lack of inclusion of accepted alternative methods.

Tab. 2: Overview of test methods included in Regulation (EC) No. 440/2008

\begin{tabular}{|c|c|c|c|c|}
\hline \multirow[t]{2}{*}{ Endpoint } & \multirow[t]{2}{*}{ Method Name } & \multirow[t]{2}{*}{ Test Type } & \multicolumn{2}{|c|}{ Regulatory Acceptance } \\
\hline & & & International & $\begin{array}{l}\text { Considered in } \\
\text { Regulation (EC) } \\
\text { No. } 440 / 2008 \\
\text { or ATP }\end{array}$ \\
\hline Acute aquatic toxicity & $\begin{array}{l}\text { Upper threshold concentration } \\
\text { step-down approach }\end{array}$ & In vivo & OECD GD 126 (2010) & no \\
\hline \multirow{4}{*}{$\begin{array}{l}\text { Acute mammalian toxicity } \\
\text { (oral) }\end{array}$} & Acute toxic class method & In vivo & OECD TG 423 (2001) & yes \\
\hline & Fixed dose procedure & In vivo & OECD TG 420 (2001) & yes \\
\hline & $\begin{array}{l}\text { Normal human keratinocyte } \\
\text { neutral red uptake (NHK NRU) } \\
\text { assay }\end{array}$ & In vitro & OECD GD 129 (2010) & no \\
\hline & $\begin{array}{l}\text { Balb/c 3T3 neutral red uptake } \\
\text { assay }\end{array}$ & In vitro & OECD GD 129 (2010) & no \\
\hline \multirow{2}{*}{$\begin{array}{l}\text { Acute mammalian toxicity } \\
\text { (inhalation) }\end{array}$} & Acute toxic class method & In vivo & OECD TG 436 (2009) & no \\
\hline & Fixed concentration procedure & In vivo & Draft TG OECD 433 & no \\
\hline
\end{tabular}




\begin{tabular}{|c|c|c|c|c|}
\hline \multirow[t]{2}{*}{ Endpoint } & \multirow[t]{2}{*}{ Method Name } & \multirow[t]{2}{*}{ Test Type } & \multicolumn{2}{|l|}{ Regulatory Acceptance } \\
\hline & & & International & $\begin{array}{l}\text { Considered in } \\
\text { Regulation (EC) } \\
\text { No. 440/2008 } \\
\text { or ATP }\end{array}$ \\
\hline Dermal penetration & In vitro skin absorption methods & In vitro & $\begin{array}{l}\text { OECD TG } 428 \text { (2004) } \\
\text { OECD GD } 28 \text { (2004) } \\
\text { Draft OECD Guidance } \\
\text { Notes (2010) }\end{array}$ & yes \\
\hline \multirow[t]{2}{*}{ Eye corrosion } & $\begin{array}{l}\text { Bovine corneal opacity } \\
\text { permeability (BCOP) test }\end{array}$ & Ex vivo & $\begin{array}{l}\text { OECD TG } 437 \text { (2009) } \\
\text { Draft OECD GD } \\
\text { on Supplement to TG } 437 \\
\text { and } 438 \text { (histopathology) } \\
\text { (2009) }\end{array}$ & yes \\
\hline & Isolated chicken eye (ICE) test & Ex vivo & $\begin{array}{l}\text { OECD TG } 438 \text { (2009) } \\
\text { Draft OECD GD } \\
\text { on Supplement to TG } 437 \\
\text { and } 438 \text { (histopathology) } \\
\text { (2009) }\end{array}$ & yes \\
\hline \multirow[t]{8}{*}{ Genotoxicity } & $\begin{array}{l}\text { Bacterial reverse mutation } \\
\text { (Ames) test }\end{array}$ & In vitro & OECD TG 471 (1997) & yes \\
\hline & In vitro cell gene mutation test & In vitro & OECD TG 476 (1997) & yes \\
\hline & $\begin{array}{l}\text { In vitro chromosomal } \\
\text { aberration test }\end{array}$ & In vitro & OECD TG 473 (1997) & yes \\
\hline & $\begin{array}{l}\text { In vitro mammalian cell } \\
\text { micronucleus test }\end{array}$ & In vitro & OECD TG 487 (2010) & no \\
\hline & $\begin{array}{l}\text { In vitro sister chromatid } \\
\text { exchange test }\end{array}$ & In vitro & OECD TG 479 (1986) & yes \\
\hline & $\begin{array}{l}\text { In vitro unscheduled DNA } \\
\text { synthesis test }\end{array}$ & In vitro & OECD TG 482 (1986) & yes \\
\hline & $\begin{array}{l}\text { Saccharomyces cerevisiae } \\
\text { gene mutation assay }\end{array}$ & In vitro & OECD TG 480 (1986) & yes \\
\hline & $\begin{array}{l}\text { Saccharomyces cerevisiae } \\
\text { mitotic recombination assay }\end{array}$ & In vitro & OECD TG 481 (1986) & yes \\
\hline \multirow[t]{4}{*}{$\begin{array}{l}\text { Immunotoxicity/ } \\
\text { Skin Sensitization }\end{array}$} & Local lymph node assay (LLNA) & In vivo & $\begin{array}{l}\text { OECD TG } 429 \text { (2002) } \\
\text { Updated OECD TG } 429 \\
(2010)\end{array}$ & yes \\
\hline & Reduced LLNA: rLLNA & In vivo & Updated OECD TG 429 (2010) & no \\
\hline & Non-radiolabelled LLNA: DA & In vivo & OECD TG 442A (2010) & no \\
\hline & $\begin{array}{l}\text { Non-radiolabelled LLNA: } \\
\text { BrdU-ELISA }\end{array}$ & In vivo & OECD TG 442B (2010) & no \\
\hline Phototoxicity & $\begin{array}{l}\text { 3T3 Neutral Red Uptake } \\
\text { Phototoxicity Test }\end{array}$ & In vitro & OECD TG 432 (2004) & yes \\
\hline $\begin{array}{l}\text { Reproductive \& } \\
\text { developmental toxicity }\end{array}$ & $\begin{array}{l}\text { Extended one-generation } \\
\text { reproductive toxicity study }\end{array}$ & In vivo & OECD TG 443 (2011) & no \\
\hline \multirow[t]{4}{*}{ Skin corrosion } & $\begin{array}{l}\text { EST-1000 human } \\
\text { reconstructed epidermis }\end{array}$ & In vitro & $\begin{array}{l}\text { OECD TG } 431 \text { (2004) } \\
\text { Draft Updated TG } 431 \text { (2009) }\end{array}$ & no \\
\hline & $\begin{array}{l}\text { Corrositex }{ }^{\circledR} \text { non-cellular } \\
\text { membrane }\end{array}$ & In vitro & OECD TG 435 (2006) & no \\
\hline & EpiSkin ${ }^{\circledR}$ human skin model & In vitro & $\begin{array}{l}\text { OECD TG } 431 \text { (2004) } \\
\text { Draft Updated TG } 431 \text { (2009) }\end{array}$ & yes \\
\hline & EpiDerm ${ }^{\mathrm{TM}}$ human skin model & In vitro & $\begin{array}{l}\text { OECD TG } 431 \text { (2004) } \\
\text { Draft Updated TG } 431 \text { (2009) }\end{array}$ & yes \\
\hline
\end{tabular}




\begin{tabular}{|c|c|c|c|c|}
\hline \multirow[t]{2}{*}{ Endpoint } & \multirow[t]{2}{*}{ Method Name } & \multirow[t]{2}{*}{ Test Type } & \multicolumn{2}{|l|}{ Regulatory Acceptance } \\
\hline & & & International & $\begin{array}{l}\text { Considered in } \\
\text { Regulation (EC) } \\
\text { No. } 440 / 2008 \\
\text { or ATP }\end{array}$ \\
\hline \multirow[t]{3}{*}{ Skin corrosion (cont.) } & $\begin{array}{l}\text { Rat skin transcutaneous } \\
\text { electrical resistance (TER) assay }\end{array}$ & Ex vivo & $\begin{array}{l}\text { OECD TG } 430 \text { (2004) } \\
\text { Draft Updated TG } 430 \text { (2009) }\end{array}$ & yes \\
\hline & SkinEthic ${ }^{T M}$ human skin model & In vitro & $\begin{array}{l}\text { OECD TG } 431 \text { (2004) } \\
\text { Draft Updated TG } 431 \text { (2009) }\end{array}$ & no \\
\hline & $\begin{array}{l}\text { Vitrolife-Skin human } \\
\text { reconstructed epidermis }\end{array}$ & In vitro & $\begin{array}{l}\text { OECD TG } 431 \text { (2004) } \\
\text { Draft Updated TG } 431 \text { (2009) }\end{array}$ & no \\
\hline \multirow[t]{3}{*}{ Skin irritation } & $\begin{array}{l}\text { EpiSkin }^{\circledR} \text { skin irritation test } \\
\text { (with MTT reduction) }\end{array}$ & In vitro & OECD TG 439 (2010) & yes \\
\hline & EpiDermTM SIT model (EPI-200) & In vitro & OECD TG 439 (2010) & no \\
\hline & SkinEthic RHE model & In vitro & OECD TG 439 (2010) & yes \\
\hline
\end{tabular}

\subsubsection{Procedure of inclusion of newly adopted OECD TGs in the TMR; reproductive toxicity}

The test methods laid down in Regulation (EC) No. 440/2008 are mostly based on existing OECD Test Guidelines (TG). The difficulties, however, start with the procedure of acceptance of a newly adopted OECD TG in the EU. There seems to be no consistent approach regarding how long after OECD acceptance, or if at all, Regulation (EC) No. 440/2008 will be adapted to include a newly adopted OECD TG. This is illustrated by the case of the OECD's adoption of TG 443 (Extended One-Generation Reproductive Toxicity Study, EOGRTS) in July 2011 that, to date, still has not been included in Regulation (EC) No. $440 / 2008$. Assessment of reproductive toxicity is required in the EU for chemicals (REACH), biocidal products (BPR), and plant protection products (PPPR). At present, the Two-Generation Reproductive Toxicity study based on OECD TG 416 of 2001 is required in the respective Regulations. However, animal numbers for reproductive toxicity testing could be reduced by up to $50 \%$ compared to the Two-Generation study by using the EORGTS (Cooper et al., 2006). Moreover, the EGORTS is designed to include additional endpoints (neurotoxicity, immunotoxicity, endocrine-mediated toxicity), which may further decrease the number of animals used for risk assessment. Therefore, it seems imperative to include the EOGRTS in the TMR and respective data requirements, as well as to comply with the measures of REACH and the TMR itself. The EC already demonstrated that it can, in fact, act to adapt Regulation (EC) No. $440 / 2008$ to the technical progress before an alternative method becomes adopted as a new OECD TG. In the case of the In vitro Skin Irritation: Reconstructed Human Epidermis Model Test, Regulation (EC) No. 440/2008 was amended in July 2009 by Regulation (EC) No. 761/2009 to include the new method as B.46 even before it was adopted as OECD TG 439 in July 2010 (The ESAC Statement concerning the in vitro skin irritation test method was published in 2007). However, the in- clusion of the EOGRTS into Regulation (EC) No. 440/2008 is still pending (no ESAC statement has been published so far for the EOGRTS).

\subsubsection{Outdated or unnecessary animal test for reproductive toxicity}

Even though test method B.34 (One Generation Reproduction Toxicity Test) lacks reference to the corresponding OECD TG, the similar text and structure indicate that B.34 presumably is based on OECD TG 415. This TG dates back to 1983 without having since been revised. REACH, the BPR, and the PPPR do not require this test method, so there is no regulatory requirement for it. Besides, two more current test methods for reproductive toxicity are now available (the Two-Generation Reproductive Toxicity Study, B.35, and the newly adopted EOGRTS, which should be the method of choice as it uses fewer animals). Therefore, the rationale behind listing B.34 in Regulation (EC) No. 440/2008 is not clear to us, and we suggest deleting test method B.34 from Regulation (EC) No. 440/2008, as it may cause duplicated testing for reproductive toxicity.

\subsubsection{Confusing/Biased emphasis of test methods for skin sensitization}

We found that the Regulation lists two methods to assess skin sensitization, one of which could be deleted or at least be specified for use only under certain circumstances: B.6 refers to the Guinea Pig Maximization or Buehler Test, B.42 to the Local Lymph Node Assay (LLNA). The LLNA is considered a reduction and refinement method in that it uses smaller numbers of animals and causes less pain and distress while providing scientific advantages when compared to the Guinea Pig Maximization or Buehler Test. In the description of method B.42, it is stated: "The LLNA is an in vivo method and, as a consequence, will not eliminate the use of animals in the assessment of allergic contact sensitizing activity. It has, however, the poten- 
tial to reduce the number of animals required for this purpose. Moreover, the LLNA offers a substantial refinement (less pain and distress) of the way in which animals are used for allergic contact sensitisation testing. The LLNA is based upon consideration of immunological events stimulated by chemicals during the induction phase of sensitisation. Unlike guinea pig tests (i.e.TG 406) the LLNA does not require that challenge-induced dermal hypersensitivity reactions be elicited. Furthermore, the LLNA does not require the use of an adjuvant, as is the case for the guinea pig maximisation test (13). Thus, the LLNA reduces animal pain and distress." Therefore, there is no rationale for listing B.6 first and thus implying the Guinea Pig Maximisation or Buehler Test could be of higher quality or significance. We suggest deleting B.6 and making B.42 the method of choice for skin sensitization testing.

\subsubsection{Further issues concerning Adaptation to Technical Progress}

Accepted alternative methods that should be included in the TMR are the In Vitro Mammalian Cell Micronucleus Test (adopted as OECD TG 487 in July 2010) and the Acute Toxic Class Method for Acute Inhalation Toxicity (adopted as OECD TG 436 in September 2009). OECD TG 487, a test method that measures a test substance's potential for causing damage to chromosomes, is intended to reduce the number of animals in further studies used to identify substances that can lead to cancer and other adverse health effects. OECD TG 436 offers refinement and reduction by applying serial steps and fixed target concentrations to rank test article toxicity. We also found that the TMR lacks reference to the Normal Human Keratinocyte Neutral Red Uptake (NHK NRU) assay and the Balb/c 3T3 Neutral Red Uptake Assay, which are included in the OECD GD No. 129 (OECD, 2010) on using cytotoxicity tests to estimate starting doses for acute oral systemic toxicity tests. This OECD GD describes how the number of animals used for acute toxicity testing in further studies could be significantly reduced by using data from the in vitro tests for estimating the starting dose for acute oral systemic toxicity tests instead of using animals in dose range finding studies.

\subsubsection{Clarity and practicability}

Newly adopted or revised alternative methods are not directly included in the text of Regulation (EC) No. 440/2008 as an update, i.e., no official version of the complete amended text of the Regulation is published. Instead, the amendments are externalized in separate Regulations. To date, two "Amending Regulations" have been published - one to update Method B.46 (In vitro Skin irritation: Reconstructed Human Epidermis Model Test) ${ }^{29}$ and the other to update Methods B.47 (Bovine Corneal
Opacity and Permeability Test Method for Identifying Ocular Corrosives and Severe Irritants) and B.48 (Isolated Chicken Eye Test Method For Identifying Ocular Corrosives and Severe Irritants) ${ }^{30}$.

An unofficial consolidated version of Regulation (EC) No. $440 / 2008^{31}$ is the only version that includes the newly adopted alternative methods in one document. However, this document is not legally binding. A disclaimer at the start of the document states: "This document is meant purely as a documentation tool and the institutions do not assume any liability for its contents." If applicants are not closely following the process of Adaptation to Technical Progress or are new to the field of alternative methods and unaware of newly accepted methods, they may easily miss the updates and method descriptions.

\subsubsection{Confusing/Biased order of test methods listed in the register of test methods in the TMR}

Another issue is the register of test methods in Regulation (EC) No. 440/2008. The order in which the methods are listed does not seem to follow a logically cogent system, but rather shows a timeline of when the methods were included, listing the newly adopted alternative methods last (e.g., in vivo skin irritation is listed as B.4. In vitro methods are only listed as B.40, B.40 bis, and B.46.) Thus applicants can easily miss the in vitro methods or consider them less significant. Therefore, we propose sorting the testing methods by toxicological endpoints (e.g., all test methods for assessment of skin corrosion listed as B.4, B.4 bis, B.4 tris, etc.). This would not only be more logical, but it would also help to clarify which methods are available for each endpoint and to facilitate the awareness of alternative methods and their use. Furthermore, while the respective in vivo test methods for skin and eye irritation (B.4 and B.5) are listed as test methods to assess "acute toxicity," the in vitro methods (B.40, B.40 bis, B.46, B.47, and B.48) are not. According to the IUPAC Compendium of Chemical Terminology ("Gold Book"), acute toxicity is defined as:

"1. Adverse effects of finite duration occurring within a short time (up to $14 d$ ) after administration of a single dose (or exposure to a given concentration) of a test substance or after multiple doses (exposures), usually within 24 h of a starting point (which may be exposure to the toxicant, or loss of reserve capacity, or developmental change, etc.)" or

"2. Ability of a substance to cause adverse effects within a short time of dosing or exposure" (Nordberg et al., 2004).

This definition also applies to effects monitored in the in vitro testing methods, thus it does not become clear why this differentiation is made. In addition to the above mentioned issue of in vitro methods being listed at the end of the register of testing methods in the TMR, the described differentiation also may im-

\footnotetext{
29 Commission Regulation (EC) No. 761/2009 of 23 July 2009 amending, for the purpose of its adaptation to technical progress, Regulation (EC) No. 440/2008 laying down test methods pursuant to Regulation (EC) No. 1907/2006 of the European Parliament and of the Council on the Registration, Evaluation, Authorisation and Restriction of $\mathrm{Chemicals} \mathrm{(REACH)}$

30 Commission Regulation (EU) No. 1152/2010 of 8 December 2010 amending, for the purpose of its adaptation to technical progress, Regulation (EC) No. 440/2008 laying down test methods pursuant to Regulation (EC) No. 1907/2006 of the European Parliament and of the Council on the Registration, Evaluation, Authorisation and Restriction of Chemicals (REACH)

31 http://eur-lex.europa.eu/LexUriServ/LexUriServ.do?uri=CONSLEG:2008R0440:20101212:en:PDF
} 
ply that the in vitro methods are less significant or less appropriate for assessing skin and eye irritation.

\subsubsection{Lacking reference to corresponding OECD TGs}

We also found inconsistencies in the structure of test method descriptions. While about $50 \%$ of the test methods listed in Part B directly refer to a related OECD TG and claim to be equivalent or based on the respective TG, the remaining method descriptions lack this reference, even though corresponding OECD TGs exist. We found this to be true for:

- B.2. Acute Toxicity (Inhalation)

- B.3. Acute Toxicity (Dermal)

- B.8. Repeated Dose (28 Days) Toxicity (Inhalation)

- B.9. Repeated Dose (28 Days) Toxicity (Dermal)

- B.15. Mutagenicity Testing and Screening for Carcinogenicity Gene Mutation - Saccharomyces cerevisiae

- B.16. Mitotic Recombination - Saccharomyces cerevisiae

- B.18. DNA Damage and Repair - Unscheduled DNA Synthesis - Mammalian Cells in vitro

- B.19. Sister Chromatid Assay in vitro

- B.20. Sex-linked Recessive Lethal Test in Drosphila melanogaster

- B.22. Rodent Dominant Lethal Test

- B.24. Mouse Spot Test

- B.25. Mouse Heritable Translocation

- B.28. Sub-chronic Dermal Toxicity Study 90-Day Repeated Dermal Dose Study Using Rodent Species

- B.29. Sub-chronic Inhalation Toxicity Study 90-Day Repeated Inhalation Dose Study Using Rodent Species

- B.30. Chronic Toxicity Test

- B.32. Carcinogenicity Test

- B.33. Combined Chronic Toxicity/Carcinogenicity Test

- B.34. One-Generation Reproduction Toxicity Test

- B.36. Toxicokinetics

- B.46. In vitro Skin irritation: Reconstructed Human Epidermis Model Test

- B.47. Bovine Corneal Opacity and Permeability Test Method for Identifying Ocular Corrosives and Severe Irritants

- B.48. Isolated Chicken Eye Test Method For Identifying Ocular Corrosives and Severe Irritants

If applicants are not familiar with adopted OECD TGs, this lack of reference may cause confusion for the applicants and difficulties with getting test data and results accepted by competent authorities. Furthermore, the descriptions of testing procedures for some of the methods mentioned above are not very detailed in that they contain no advice or reference to the OECD GD on Humane Endpoints, whereas the corresponding OECD TGs do. In case a method involves testing on vertebrate animals, this may give rise to a lack of consideration of humane endpoints and other animal welfare concerns, as the missing reference to corresponding OECD TGs may result in testing on animals that does not follow standard testing protocols regarding consideration of animal welfare, rules for choice of appropriate animal species, sex, number, housing, feeding, and the actual testing procedure.

\subsection{REACH (Regulation (EC) No. 1907/2006)}

Animal welfare and alternatives to animal testing are considered extensively in the text of the REACH regulation. Of the EU legislations we compared, REACH is the most consistent one regarding wording, design, structure of data requirements, and implementation of principles regarding animal welfare. Not only does it include numerous references and provisions on the necessity of replacing and reducing testing on animals and the promotion and development of alternative methods in its Regulation text (recitals and articles) and Annexes, but it also gives detailed and extensive instructions on how to avoid testing on animals. Most importantly, regarding objectives and general rules of REACH, Article 25, paragraph 1 requires that: "In order to avoid animal testing, testing on vertebrate animals for the purposes of this Regulation shall be undertaken only as a last resort. It is also necessary to take measures limiting duplication of other tests." In Article 13, paragraph 1 it is stated that: "In particular for human toxicity, information shall be generated whenever possible by means other than vertebrate animal tests, through the use of alternative methods, for example, in vitro methods or qualitative or quantitative structure-activity relationship models or from information from structurally related substances (grouping or read-across)." REACH also introduced principles like mandatory sharing of data involving testing on vertebrate animals (Recitals 33, 49, 50, 51, 110; Article 25, paragraphs 2 and 3; Article 27; Article 30; Article 53). This included the set-up of Substance Information Exchange Forums (SIEF) consisting of potential registrants of the same substance who must collaborate within the forum on obtaining and sharing data on the substance, ensuring that unnecessary animal testing is avoided (Recital 54; Article 29; Article 30). REACH enables joint submissions of data by registrants who apply for authorization of the same substance (Recital 33; Article 11; Article 25, paragraph 2). The Regulation also introduced a "scrutiny period" of 45 days for proposals for tests on vertebrate animals. These proposals have to be published on ECHA's website. This allows third parties to submit scientifically valid information and studies addressing the relevant substance and hazard endpoint information and may show that this data is sufficient and the proposed test can be rejected (Recital 64; Article 40, paragraph 2). In contrast to other EU legislation, REACH distinguishes itself by providing its own Annex that includes advice on measures to avoid and reduce testing on animals (Annex XI: General Rules for Adaptation of the Standard Testing Regime set out in Annexes VII to X).

Annexes VII to X list the standard information required for a registration, including endpoints that need to be assessed for human toxicology and eco-toxicology for each tonnage level. For the lowest tonnage level, i.e., substances that are manufactured or imported in quantities of 1 ton per year or less, the standard requirements are listed in Annex VII. The advice given in Annex VI on fulfilling the requirements of Annexes VI to XI states that every time a new tonnage level is reached, the requirements of the corresponding Annex have to be added. For each registration, the precise information requirements will differ, according to tonnage, use, and exposure. This means that the Annexes are 
to be considered as a whole, e.g., for a substance that is manufactured or imported in quantities of 1000 tons per year or more, the data requirements of the corresponding Annex X have to be fulfilled, but in addition, the requirements of the Annexes VII, VIII and IX have to be fulfilled as well.

Each Annex (VII to X) starts with an introduction explaining the specific rules for adaptation of the standard information. It also explains that a registrant may adapt the required standard information set out in column 1 of this Annex according to the general rules contained in Annex XI, with the exception of the section on substance-tailored exposure waiving. The Annexes are divided into two columns, one that lists the standard information requirements and a second one comprising the rules for adaptation according to which the required standard information may be omitted, replaced by other information, provided at a different stage, or adapted in another way. In addition to these specific rules, a registrant also may adapt the required standard information set out in column 1 of a respective Annex according to the general rules contained in Annex XI, with the exception of section 3 on substance-tailored exposure waiving. The introduction also contains a footnote stating that conditions for not requiring a specific test that are set out in the appropriate test methods in the Commission Regulation on test methods, as specified in Article 13 (3), which are not repeated in column 2 , also apply. For an overview of the detailed analysis of test methods in REACH, please see Table 3.

However, in spite of generally being structured logically and designed consistently, inconsistencies can be found in the standard information required in $\mathrm{REACH}$ Annexes VII to X. The majority of the methods that should be used for assessment of individual endpoints are not specified, e.g., Annex VII simply requires "in vitro studies" for assessment of both skin irritation and corrosion and does not refer to certain testing protocols or OECD TGs. This is consistent in so far as REACH also required the adoption of a Test Methods Regulation that lays down standard testing methods to fulfill data requirements for REACH. This requirement was implemented by the adoption of Regulation (EC) No. 440/2008. But there are some endpoints in REACH that refer to pre-assigned testing methods or OECD TGs. For example, testing for aquatic toxicity involves the Fish early-life stage (FELS) toxicity test (OECD TG 210), the Fish short-term toxicity test on embryo and sac-fry stages (OECD TG 212), and the Fish juvenile growth test (OECD TG 215). Assessment of reproductive and developmental toxicity includes reference to OECD TG 421 or 422 for Reproductive/Developmental toxicity screening and to test method B.31 of the TMR, Regulation (EC) No. 440/2008 and to OECD TG 414. It is not clear why these differentiations are made, as adopted OECD TGs exist for almost all endpoints listed in the Annexes VII to X, as do test methods in Regulation (EC) No. 440/2008.

It must be stressed that all reference to or determination of specified test methods or OECD TGs in REACH makes risk assessment approaches inflexible and hard to keep scientifically and technically up to date when new alternative methods become accepted or adopted as OECD TGs. This state of affairs also promotes possible inconsistencies between related EU legislation, as test methods determined in REACH may be different from those in data requirements for Biocidal Products or Plant Protection Products. Furthermore, adaptation to technical progress is likely to be implemented faster for the test methods included in Regulation (EC) No. 440/2008, which also applies to the data requirements laid down in the upcoming EU Biocidal Products Regulation and is referred to in the data requirements in the Annexes to the PPPR. To help eliminate these inconsistencies, standard information requirements in REACH should be limited to endpoints that need to be assessed without specification or determination of test methods, as these might change with technical progress.

Tab. 3: Overview of test methods included in Regulation EC No. 1907/2006

\begin{tabular}{|c|c|c|c|c|c|}
\hline \multicolumn{2}{|l|}{ Endpoint } & \multicolumn{4}{|c|}{ Test type required in Regulation (EC) No. 1907/2006 } \\
\hline & & Annex VII & Annex VIII & Annex IX & Annex X \\
\hline \multirow[t]{5}{*}{ Aquatic toxicity } & Short-term toxicity testing on fish & - & in vivo* & - & - \\
\hline & Long-term toxicity testing on fish & - & in vivo* & in vivo* & - \\
\hline & $\begin{array}{l}\text { Fish early-life stage (FELS) } \\
\text { toxicity test }\end{array}$ & - & - & in vivo* & - \\
\hline & $\begin{array}{l}\text { Fish short-term toxicity test on } \\
\text { embryo and sac-fry stages }\end{array}$ & - & - & in vivo* & - \\
\hline & Fish juvenile growth test & - & - & in vivo* & - \\
\hline \multicolumn{2}{|c|}{ Acute mammalian toxicity (oral) } & in vivo* & - & - & - \\
\hline \multicolumn{2}{|c|}{ Acute mammalian toxicity (inhalation) } & - & in vivo* & - & - \\
\hline \multicolumn{2}{|c|}{ Acute mammalian toxicity (dermal) } & - & in vivo* & - & - \\
\hline \multicolumn{2}{|c|}{ Bioaccumulation in aquatic species, preferably fish } & - & - & in vivo* & - \\
\hline \multicolumn{2}{|l|}{ Carcinogenicity } & - & - & - & in vivo* \\
\hline \multicolumn{2}{|c|}{ Dermal penetration } & - & - & - & - \\
\hline
\end{tabular}




\begin{tabular}{|c|c|c|c|c|c|}
\hline \multicolumn{2}{|l|}{ Endpoint } & \multicolumn{4}{|c|}{ Test type required in Regulation (EC) No. 1907/2006 } \\
\hline & & Annex VII & Annex VIII & Annex IX & Annex X \\
\hline \multicolumn{2}{|l|}{ Effects on birds } & - & - & - & $\begin{array}{l}\text { in vivo* } \\
\text { (Long-term or } \\
\text { reproductive } \\
\text { toxicity to birds) }\end{array}$ \\
\hline \multicolumn{2}{|l|}{ Eye irritation } & in vitro* & in vivo* & - & - \\
\hline \multicolumn{2}{|l|}{ Genotoxicity } & $\begin{array}{l}\text { in vitro } \\
\text { (In vitro gene } \\
\text { mutation study } \\
\text { in bacteria) }\end{array}$ & $\begin{array}{l}\text { in vitro* } \\
\text { (In vitro cyto- } \\
\text { genicity study in } \\
\text { mammalian cells } \\
\text { or in vitro micro- } \\
\text { nucleus study + } \\
\text { in vitro gene } \\
\text { mutation study in } \\
\text { mammalian cells) } \\
\text { in vivo* }\end{array}$ & in vivo* & $\begin{array}{l}\text { in vivo* } \\
\text { (In vivo } \\
\text { somatic cell } \\
\text { test) }\end{array}$ \\
\hline \multicolumn{2}{|l|}{ Phototoxicity } & - & - & - & - \\
\hline \multirow{3}{*}{$\begin{array}{l}\text { Repeated Dose } \\
\text { Toxicity }\end{array}$} & Short-term (28 days) & - & in vivo* & in vivo* & - \\
\hline & Sub-chronic (90 days) & - & in vivo* & in vivo* & - \\
\hline & Long-term ( $\geq 12$ month) & - & - & - & in vivo* \\
\hline \multirow[t]{3}{*}{$\begin{array}{l}\text { Reproductive \& } \\
\text { developmental } \\
\text { toxicity }\end{array}$} & $\begin{array}{l}\text { Reproductive/Developmental } \\
\text { toxicity screening }\end{array}$ & - & $\begin{array}{l}\text { in vivo* } \\
\text { (Screening for } \\
\text { reproductive/ } \\
\text { developmental } \\
\text { toxicity (OECD } \\
\text { TG } 421 \text { or } 422) \text { ) }\end{array}$ & - & - \\
\hline & Developmental toxicity study & - & - & $\begin{array}{l}\text { in vivo* } \\
\text { (Pre-natal de- } \\
\text { velopmental } \\
\text { toxicity study } \\
\text { (Regulation } \\
\text { (EC) No. } 440 / \\
2008, \\
\text { Method B.31 } \\
\text { or OECD TG 414)) }\end{array}$ & $\begin{array}{l}\text { in vivo } \\
\text { (Developmental } \\
\text { toxicity study } \\
\text { (OECD TG 414)) }\end{array}$ \\
\hline & $\begin{array}{l}\text { Two-generation reproductive } \\
\text { toxicity study }\end{array}$ & - & - & in vivo* & in vivo* \\
\hline \multicolumn{2}{|l|}{ Skin corrosion } & in vitro* & - & - & - \\
\hline \multicolumn{2}{|l|}{ Skin irritation } & in vitro* & in vivo* & - & - \\
\hline \multicolumn{2}{|c|}{ Skin Sensitisation } & $\begin{array}{l}\text { in vivo* } \\
\text { (LLNA) }\end{array}$ & - & - & - \\
\hline \multicolumn{2}{|l|}{ Toxicokinetics } & - & $\begin{array}{l}\text { Assessment of } \\
\text { relevant available } \\
\text { information }\end{array}$ & - & - \\
\hline
\end{tabular}

*: Testing requirements marked with an asterisk indicate that specific rules for adaptation of these requirements apply. 


\subsection{Biocidal Products}

The proposal for a BPR that was published by the EC in 2009 and the following amended texts of the Regulation after first and second reading adopt principles and ideas that were introduced with REACH, including first and foremost, the objective that testing on vertebrate animals for the purpose of the Regulation should be undertaken only as a last resort (Article 62, paragraph 1). The BPR now also requires that, regarding transitional measures concerning active substances evaluated under Directive 98/8/EC, every effort shall be made to avoid additional testing on vertebrate animals (Article 90, new). Like $\mathrm{REACH}$, the BPR requires the sharing of data on tests that involve vertebrate animals as a means to reduce animal testing and prohibits the duplication of tests on vertebrate animals. It also includes several references that point out the importance of minimizing the number of tests on animals and encouraging the generation of information by alternative means not involving tests on animals. When compared, REACH and the BPR follow a similar structure, i.e., drafting of the BPR obviously was based on and designed to be in accordance with REACH, unlike the Regulations that lay down the data requirements for the PPPR. REACH and the BPR each include an Annex that describes general rules for the adaptation of the data requirements, such as the waiving of data requirements or the weight of evidence approach (Annex IV in BPR, Annex XI in REACH). Annexes II and III of the BPR include the data requirements for active substances and biocidal products. As in $\mathrm{REACH}$, the data requirements comprise two columns, one that lists the standard information required (endpoints) and one that describes rules for the adaptation of these requirements. The BPR distinguishes between a core data set (CDS) that has to be submitted for all substances and an additional data set (ADS). According to the introduction to Annex II and III, "the data elements to be provided for a specific active substance or biocidal product shall be determined by considering each of the ADS data elements indicated in the Annex taking into account, inter alia, the physical and chemical properties of the substance, existing data, information which is part of the CDS and the types of products in which the active substance will be used and the exposure patterns related to these uses." Furthermore, the introductions to Annexes II and III state that: "In light of the importance of reducing testing on vertebrate animals, column 3 of the Annex II/III table gives specific indications for the adaptation of some of the data elements which might require the use of such tests on vertebrate animals," and that: "New tests involving vertebrate animals shall be conducted as the last available option to comply with the data requirements set out in this Annex when all the other data sources have been exhausted. In-vivo testing with corrosive substances at concentration/dose levels causing corrosivity shall also be avoided." In terms of consistency, it is helpful that the BPR, in most cases, uses the same wording for description of endpoints and rules for adaptation of the data requirements as in $\mathrm{REACH}$.

In spite of the efforts to bring the BPR in line with REACH, we found several issues in consistency, clarity of information, and adaptation to technical progress within the BPR that are not in line with the intentions of both REACH and the TMR in the
EC's proposal, the Council's official position at first reading, and the EP's report for the second reading. In addition, several areas remain where, by applying scientifically robust non-animal test methods and integrated testing strategies, the numbers and suffering of animals could be further reduced without compromising human health or environmental protection, For an overview of the detailed analysis of test methods in the BPR, see Table 4.

\subsubsection{Lacking reference to in vitro methods for skin irritation and corrosion}

In the BPR, the assessment of skin irritation and skin corrosion are part of the CDS required for hazard identification of substances. For both skin irritation and skin corrosion, accepted alternative methods are available that can either partially or fully replace the respective in vivo test. For skin irritation and corrosion, the OECD provides one in vitro test guideline, the Reconstructed Human Epidermis Test Method (OECD TG 439), which was finally adopted on July 23, 2010. Depending on requirements by the respective competent authorities, it can serve as a full replacement for the traditional in vivo test. For skin corrosion, three OECD TGs are available: the Transcutaneous Electrical Resistance Test (TER) (OECD TG 430), the Human Skin Model Test (OECD TG 431), and the In Vitro Membrane Barrier Test Method for Skin Corrosion (OECD TG 435) which can be included in an integrated testing strategy and thus help to reduce in vivo testing. The tests were adopted by the OECD on November 23, 2004 (TG 430 and 431) and August 17, 2006 (TG 435), respectively. These methods can, if included in a tiered testing scheme for skin corrosion, help identify corrosive and severely irritating substances and thus reduce further in vivo testing. If there is a positive result in one of these tests, no further testing is required, and the substance can be classified as irritating/corrosive to the skin. But even though the above mentioned alternative methods have already been included in the TMR (B.46, B.40, and B.40 bis, respectively), reference to these alternative methods is still lacking in the BPR. Instead, the only means of considering the $3 \mathrm{Rs}$ in the requirements for eye irritation testing in the BPR is reference to the "Sequential Testing Strategy for Skin Irritation and Corrosion," which is included as an appendix to the description of the in vivo skin irritation and corrosion test method (B.4) in the TMR. However, when referring to validated in vitro tests, the appendix only mentions the Transcutaneous Electrical Resistance Test. The newly adopted OECD TG 439 (on which B.46 is based) is only mentioned in a reference. In addition, the introduction of the appendix states that the strategy "is not an integral part of the testing method." Furthermore, the strategy is based on a strategy that was originally developed at an OECD workshop in 1996 (OECD, 1996). As this strategy was not adapted to technical progress before it was included in the TMR, it does not even mention recently accepted alternative methods in the "Description of the evaluation and testing strategy" included in the appendix, as it dates back to before their adoption by the OECD. To avoid confusion for applicants and to ensure the consideration of all accepted alternative methods for skin irritation and corrosion, it would be necessary to update the testing strategy as well. 


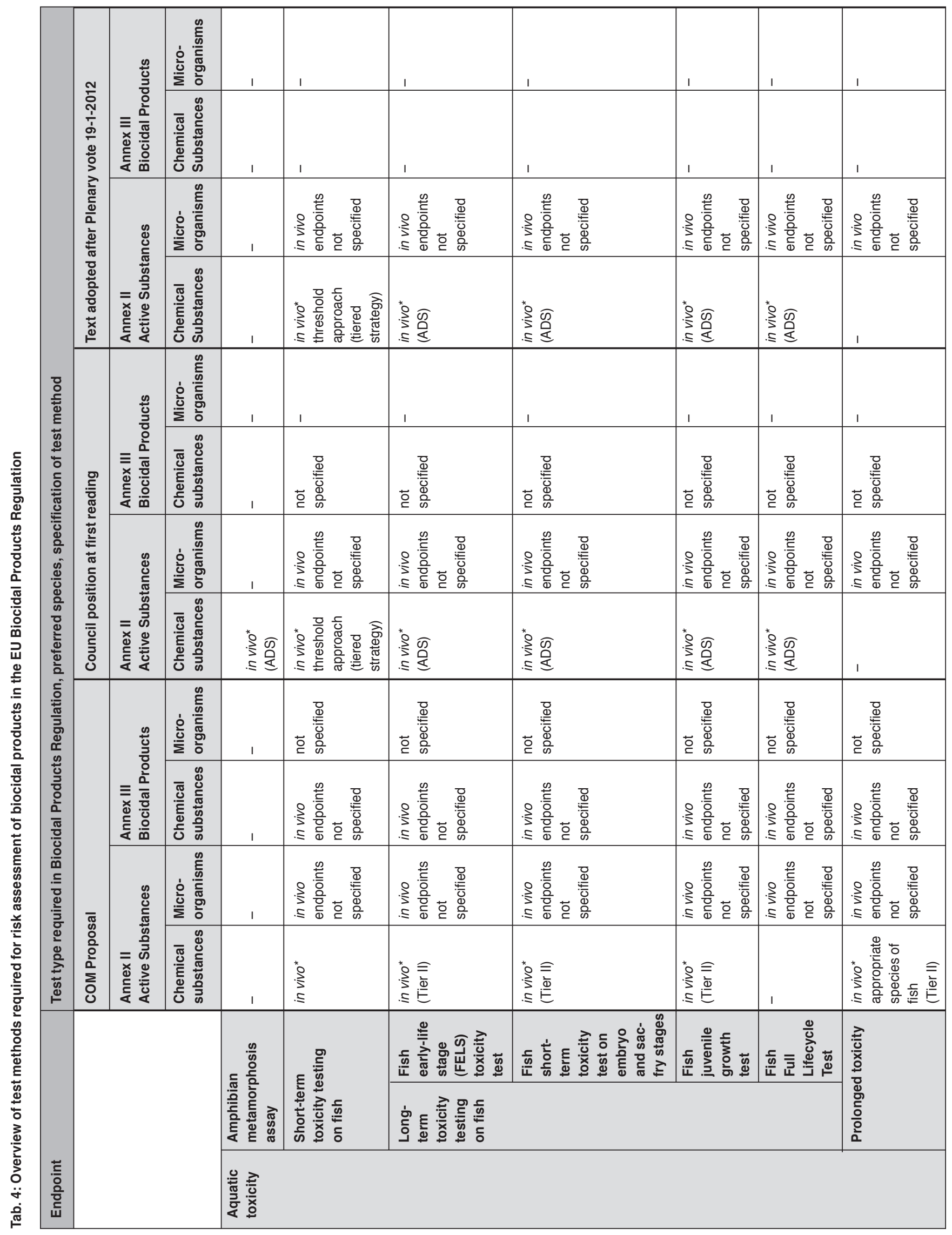


皿

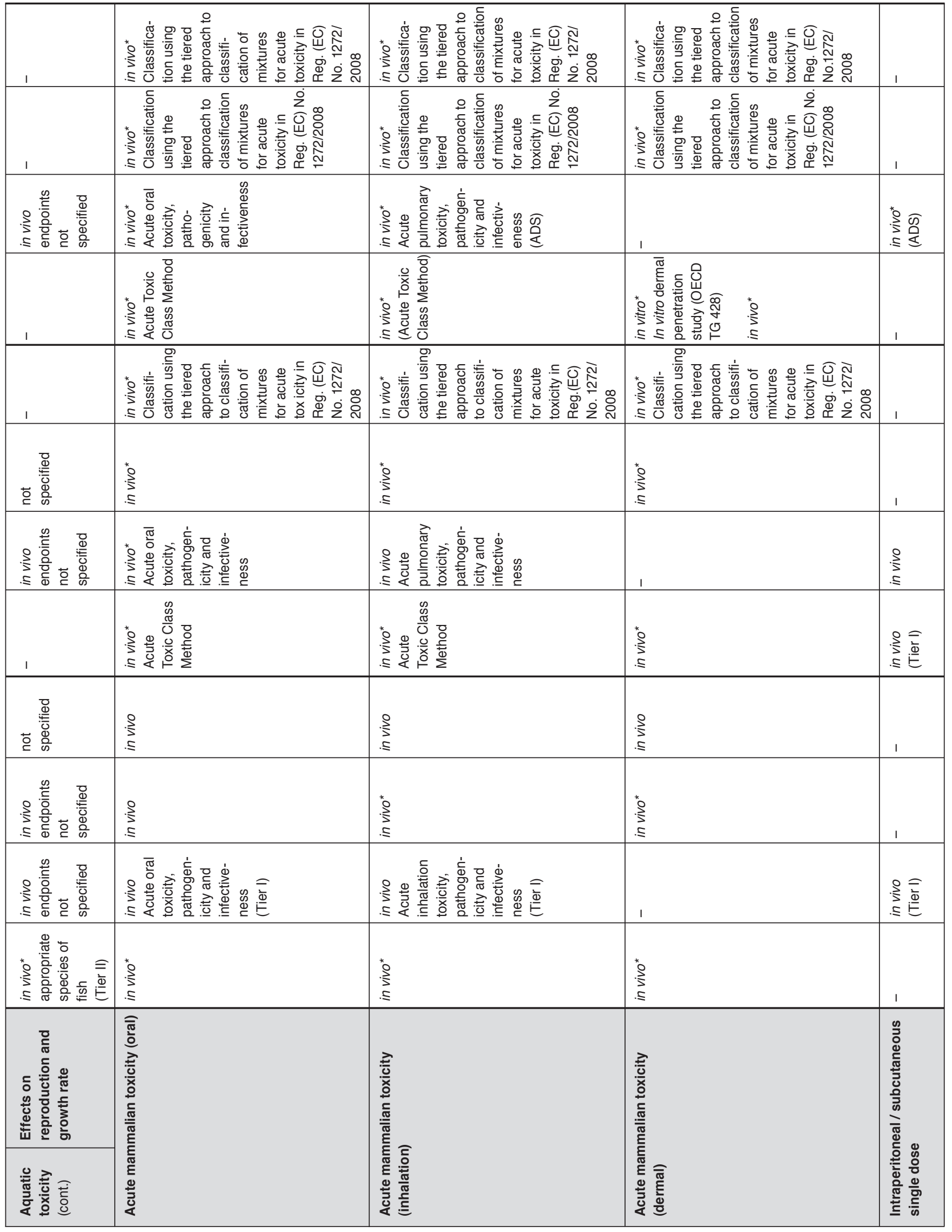




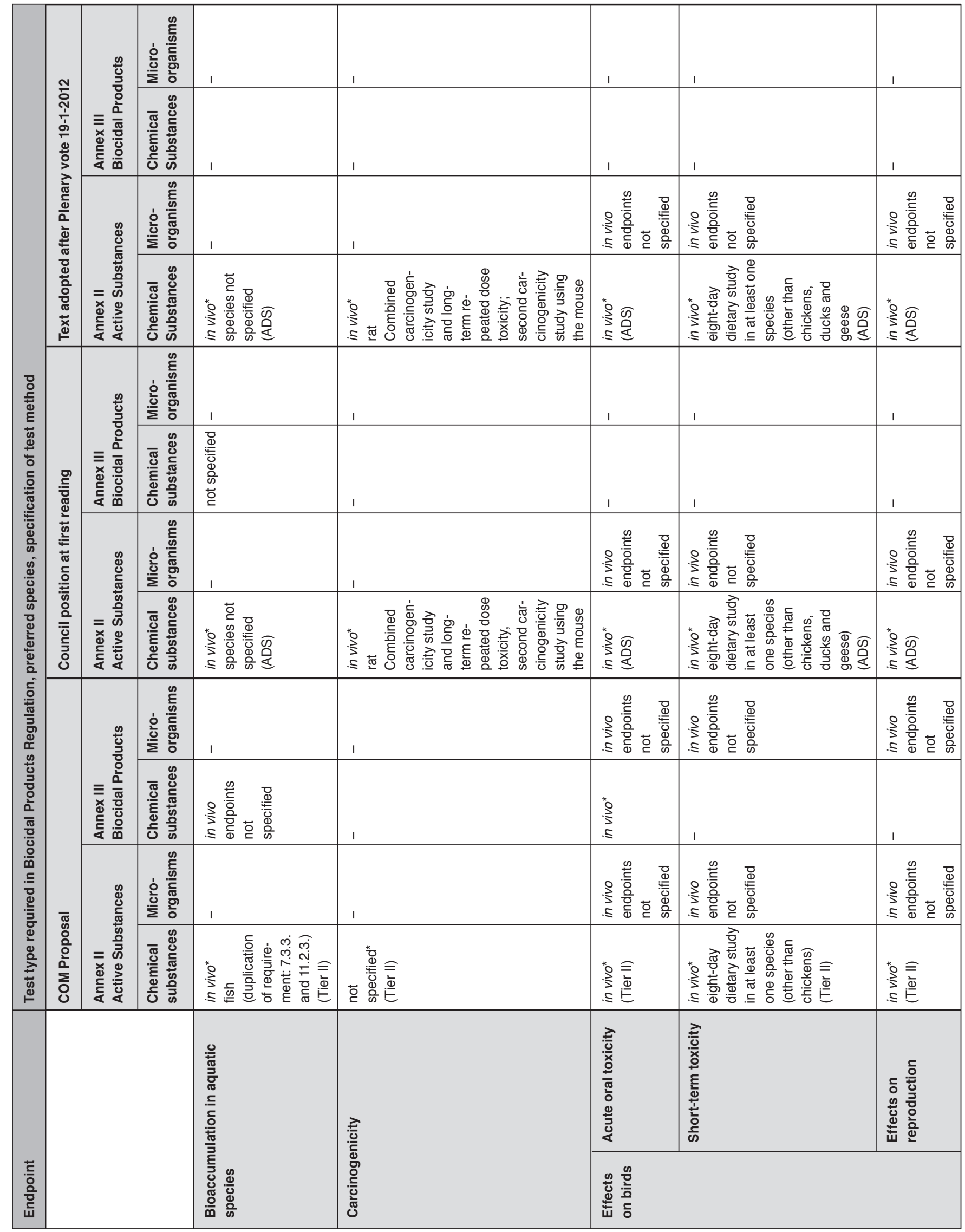




\begin{tabular}{|c|c|c|c|c|}
\hline 1 & 1 & 1 & 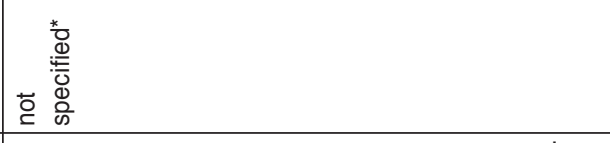 & 1 \\
\hline 1 & 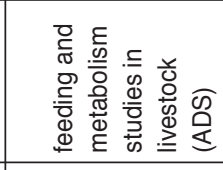 & 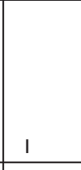 & 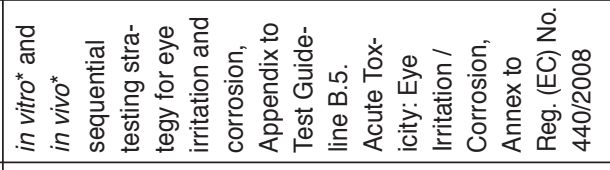 & 1 \\
\hline 1 & & 1 & 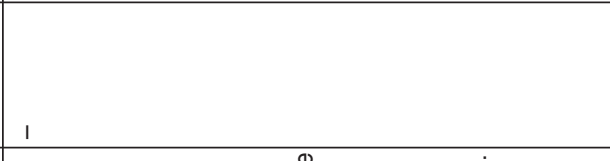 & 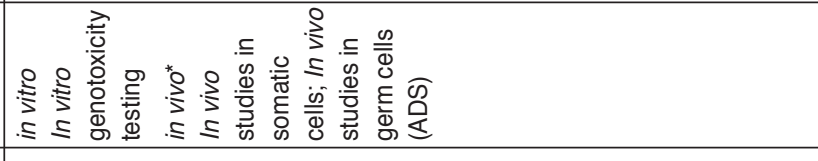 \\
\hline 帘商 & 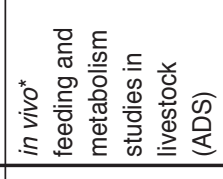 & 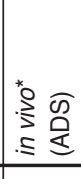 & 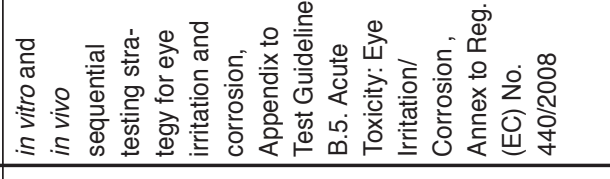 & 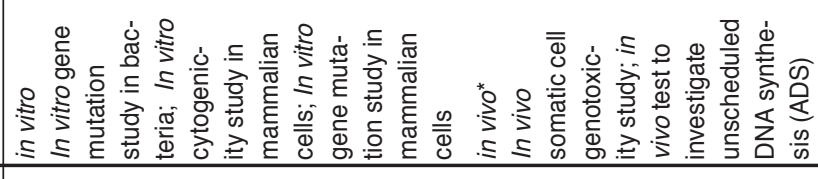 \\
\hline 1 & 1 & । & 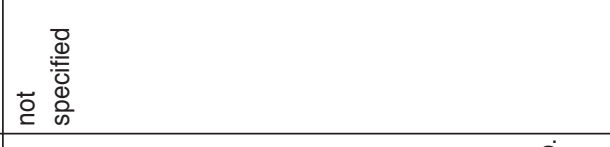 & 1 \\
\hline 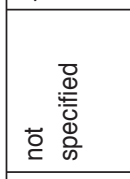 & 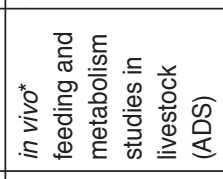 & 1 & 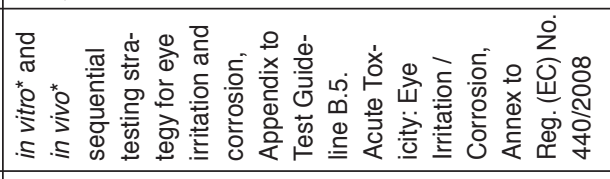 & 1 \\
\hline 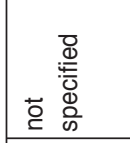 & 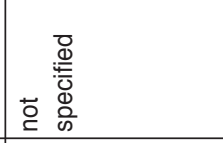 & 1 & & 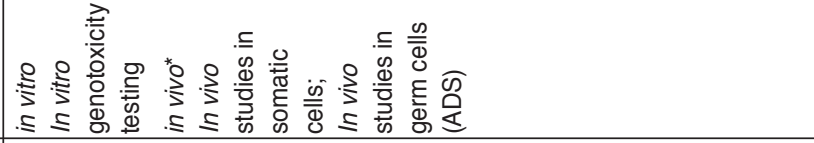 \\
\hline 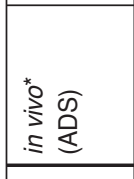 & 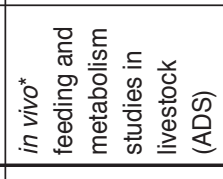 & 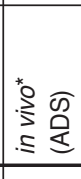 & 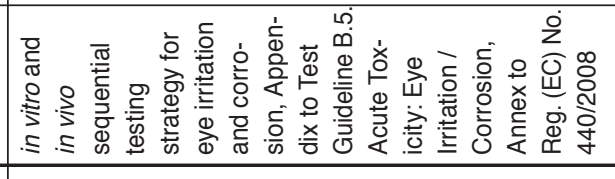 & 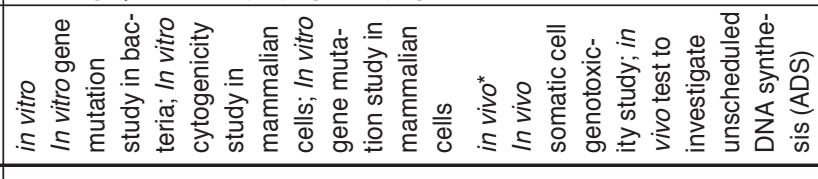 \\
\hline 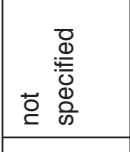 & 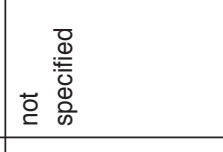 & 1 & 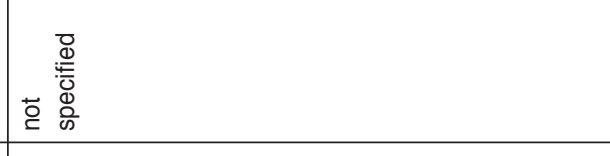 & 1 \\
\hline 1 & 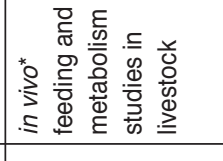 & 1 & 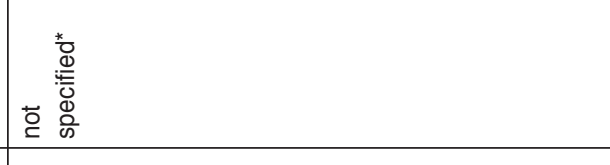 & 1 \\
\hline 1 & & 1 & & 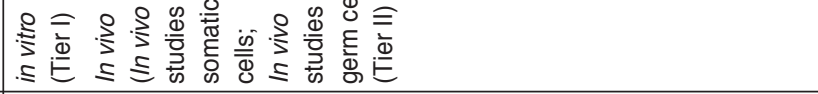 \\
\hline 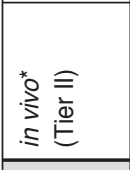 & 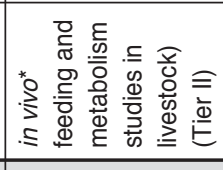 & , & 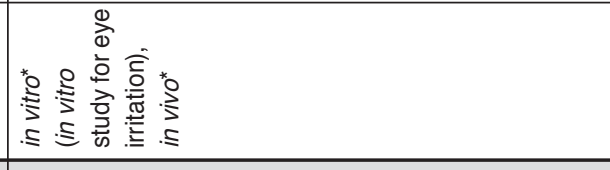 & 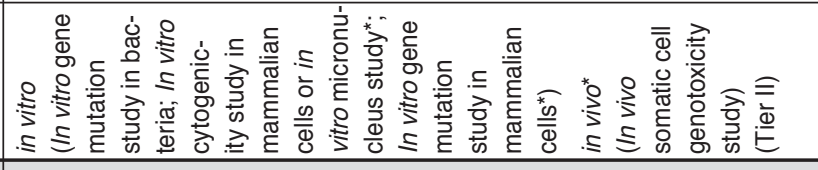 \\
\hline 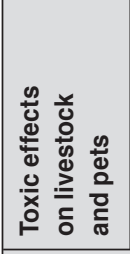 & 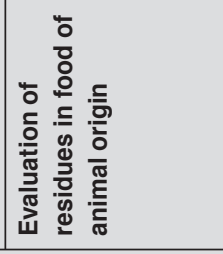 & \multirow{2}{*}{ 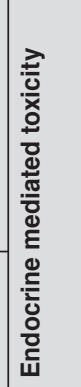 } & \multirow[b]{2}{*}{ 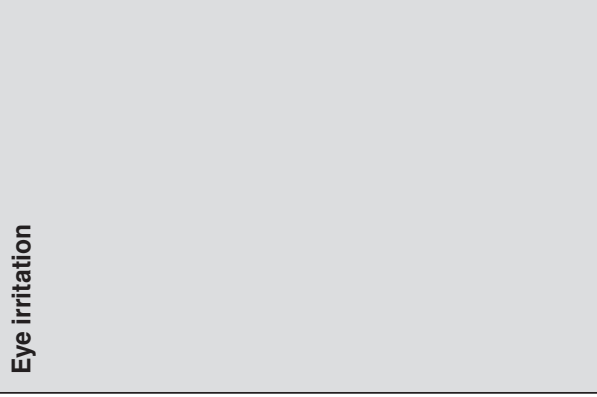 } & \multirow{2}{*}{ 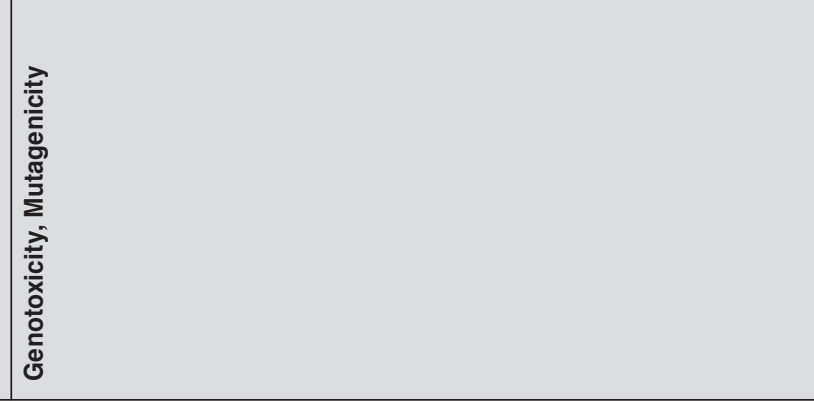 } \\
\hline 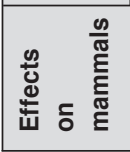 & & & & \\
\hline
\end{tabular}




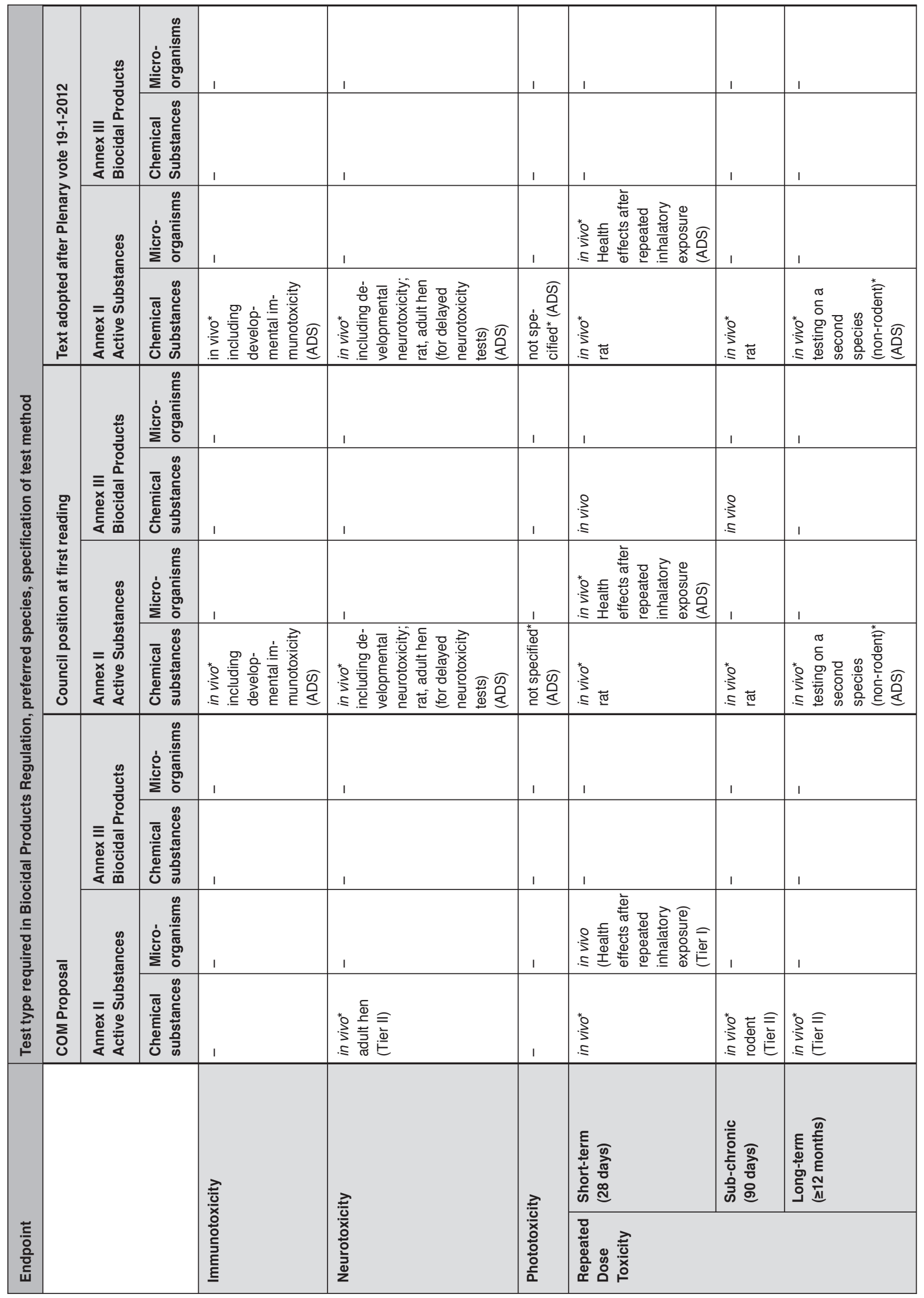




\begin{tabular}{|c|c|c|c|c|}
\hline 1 & 1 & 1 & 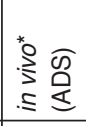 & 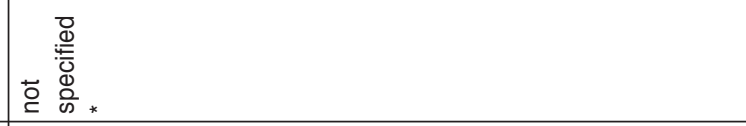 \\
\hline 1 & 1 & 1 & 总 & 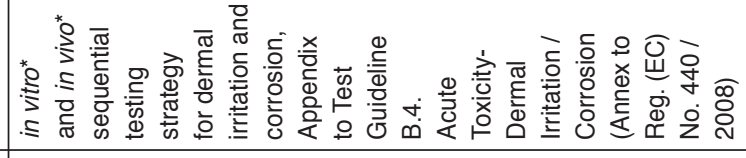 \\
\hline 1 & 1 & 1 & 1 & 1 \\
\hline 1 & 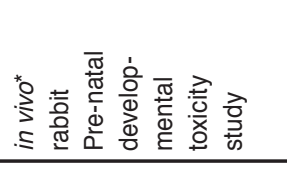 & 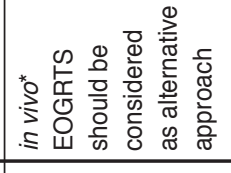 & 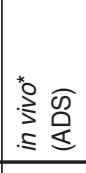 & 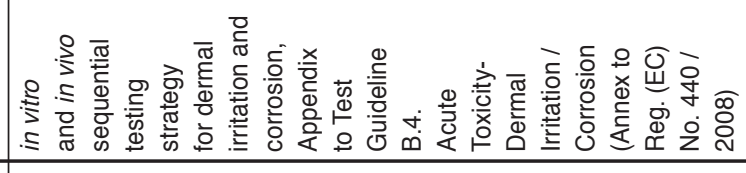 \\
\hline 1 & 1 & 1 & 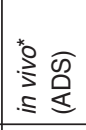 & 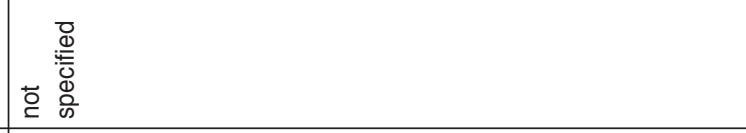 \\
\hline 1 & 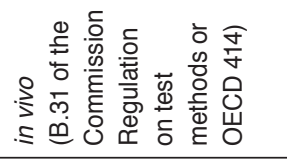 & $\begin{array}{l}\stackrel{0}{s} \\
\stackrel{3}{\leq} \\
.5\end{array}$ & 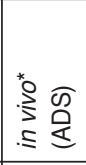 & 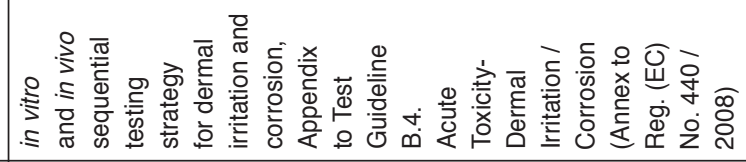 \\
\hline 1 & 1 & 1 & 1 & 1 \\
\hline 1 & 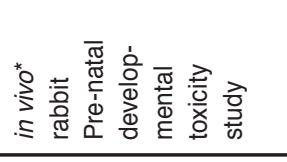 & 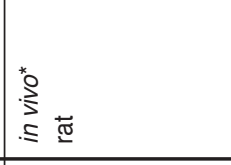 & 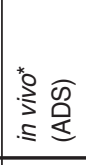 & 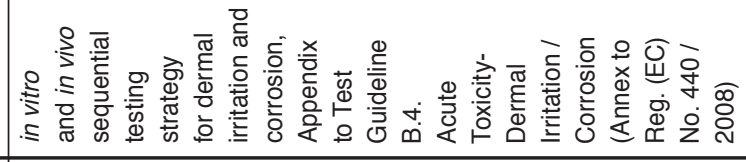 \\
\hline 1 & 1 & 1 & 1 & 1 \\
\hline 1 & 1 & 1 & 1 & 1 \\
\hline 1 & 1 & 1 & 1 & 1 \\
\hline 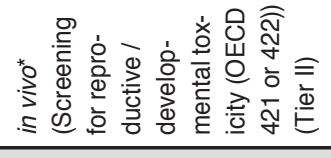 & 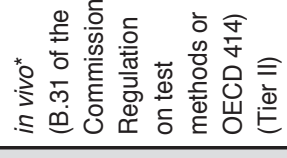 & 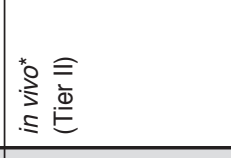 & 1 & 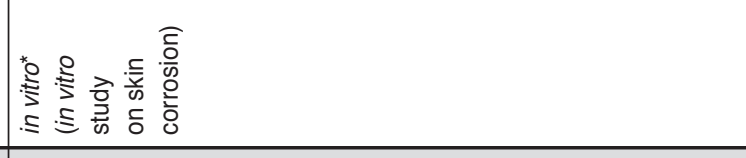 \\
\hline 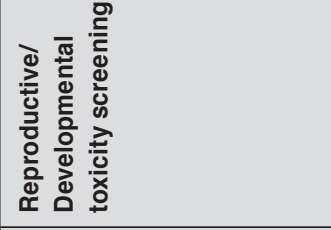 & 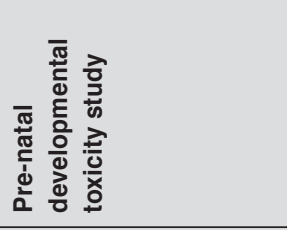 & 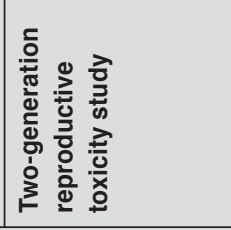 & \multirow{2}{*}{ 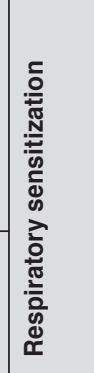 } & \multirow{2}{*}{ 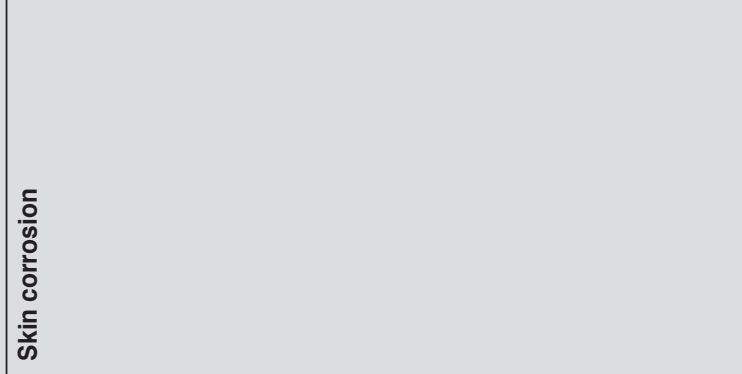 } \\
\hline 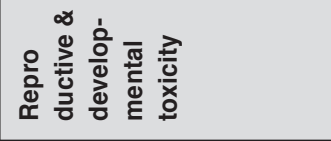 & & & & \\
\hline
\end{tabular}




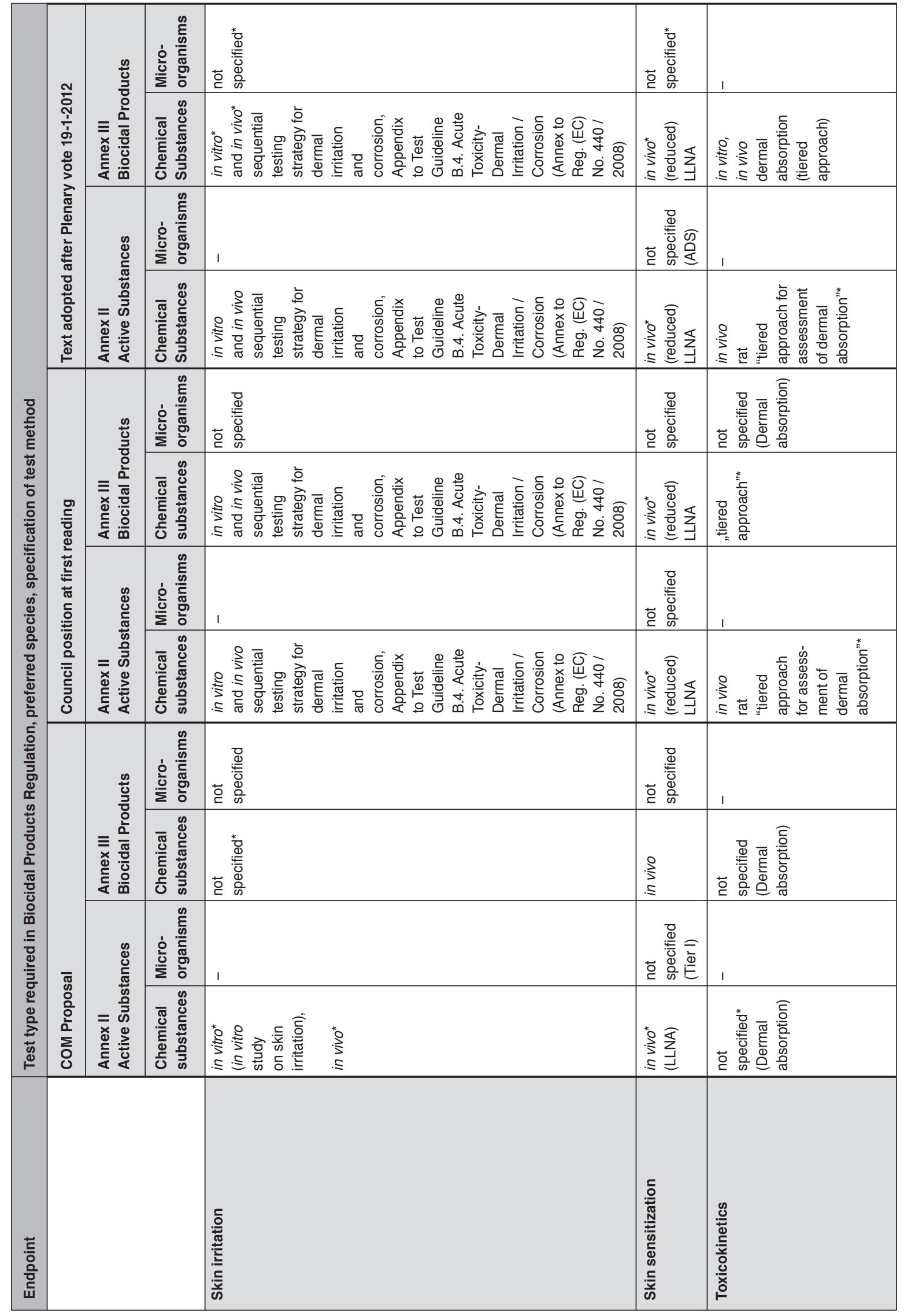

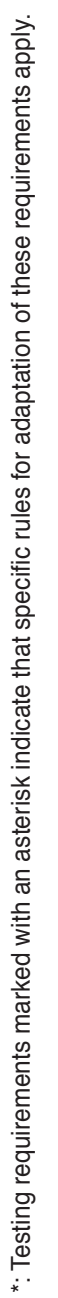




\subsubsection{Lacking reference to ex vivo methods for eye irritation}

Similar issues can be identified for eye irritation. Like skin irritation and corrosion, eye irritation is an endpoint that is required for the CDS in the BPR. Internationally accepted alternative methods are available that can partly replace the in vivo test. For eye irritation, the OECD provides two ex vivo test guidelines, the Bovine Corneal Opacity and Permeability Test Method for Identifying Ocular Corrosives and Severe Irritants (OECD TG 437) and the Isolated Chicken Eye Test Method for Identifying Ocular Corrosives and Severe Irritants (OECD TG 438). Both were adopted on September 7, 2009. Even though they were already included in the TMR in 2010 (B.47 and B.48, respectively), reference to these alternative methods is still lacking in the data requirements of the BPR. As for skin irritation and corrosion, the BPR refers to the TMR, in this case to the "Sequential Testing Strategy for Eye Irritation and Corrosion" included as an appendix to the description of the in vivo eye irritation and corrosion test method (B.5). This testing strategy is also "not an integral part of testing method," according to the introduction of the appendix, and it does not mention the accepted alternative methods in the "Description of the evaluation and testing strategy" included in the appendix, as this was developed in 1996, long before their adoption by the OECD. Likewise, an update of the testing strategy in the TMR would be necessary to reduce confusion for applicants and to ensure the consideration of all accepted alternative methods for eye irritation and corrosion.

\subsubsection{Introduction of new endpoint that lacks standard testing method}

The BPR introduces the requirement to assess the endpoint of "respiratory sensitization". No existing OECD TG or validated testing protocol is available at present for this endpoint, so this data requirement is likely to cause confusion and testing on animals that may not be in line with the provisions of the Directive 2010/63/EU and Good Laboratory Praxis (GLP), so difficulties may arise, not only with respect to animal welfare issues but also with acceptance of testing data and results by competent authorities.

\subsection{Plant Protection Products}

The Plant Protection Products Regulation (PPPR), Regulation (EC) No. 1107/2009, also includes several recitals and articles that refer to the development and promotion of alternative methods and the importance of replacing animal studies. In Recital 11, the Regulation states that "The development of non-animal test methods should be promoted in order to produce safety data relevant to humans and to replace animal studies currently in use." The Regulation also adopts the objective of REACH that testing on vertebrate animals for the purpose of the Regulation should be minimized and only be undertaken as a last resort (Recital 40; Article 62). Likewise, it extends these provisions to discourage duplication of tests and studies on vertebrate animals and includes provisions on the sharing of data in studies involving testing on vertebrate animals. Regulation (EC) No. $1107 / 2009$ also introduces new measures to minimize animal testing. In Article 7 (d) and Article 33 (3) (c), it is laid down that the summary dossier shall include: "for each test or study involving vertebrate animals, a justification of the steps taken to avoid animal testing and duplication of tests and studies on vertebrate animals;" Article 18 (b) requires that: the data submitted has to include "measures to minimise animal testing, in particular the use of non-animal test methods and intelligent testing strategies."

Nonetheless, Regulation (EU) No. 544/2011 (active substances) and Regulation (EU) No. 545/2011 (plant protection products) lack reference to animal welfare and the importance of minimizing animal testing. In contrast to the data requirements of the BPR, which are designed with consideration of those in REACH, the design and structure, and even the wording of the data requirements for the PPPR differ significantly from the other two Regulations because they are obviously based on the old Directive 91/414/EEC. This approach in itself introduces inconsistencies between the respective Regulations. Also, in terms of clarity and practicability, the structure of the data requirements in Regulation (EU) No. 544/2011 and Regulation (EU) No. 545/2011 is confusing and unclear. Endpoints (or standard information requirements) and rules for adaptation of these data requirements are not divided into two columns but are presented in running text and bullet points, making it difficult to distinguish which data must always be presented and which only has to be presented in special cases or where the data requirement can be adapted.

We identified further inconsistencies and failures to adapt the data requirements to the technical progress in the two Regulations. For an overview of the test methods in Regulation (EU) No. 544/2011 and Regulation (EU) No. 545/2011, see Table 5.

\subsubsection{Lacking reference to accepted alternative methods for skin and eye irritation}

Even though accepted alternative methods for both skin irritation and eye irritation are available (as described in 6.3) and are included in the TMR, Regulation (EU) No. 544/2011 and Regulation (EU) No. 545/2011 still exclusively require in vivo testing without even referring to in vitro methods and/or a tiered testing approach. This is not only an unacceptable state of affairs but also clearly violates the provisions of the Directive 2010/63/EU.

\subsubsection{Lacking reference to accepted alternative methods for skin sensitization}

While Regulation (EC) No. 440/2008 also includes the LLNA as a test method to assess skin sensitization, and REACH as well as the BPR refer to the LLNA as being the method of choice, the PPPR restricts the test methods for the assessment of this endpoint to the Guinea Pig Maximization Test (B.6 in Regulation (EC) No. 440/2008), which is considered to require more animals and to cause more pain and distress to each of the animals.

\subsubsection{Inconsistent terminology}

In contrast to all other data requirements we analyzed, which consistently use the term "dermal" when addressing toxic effects to the skin, Regulation (EU) No. 544/2011 and Regulation 


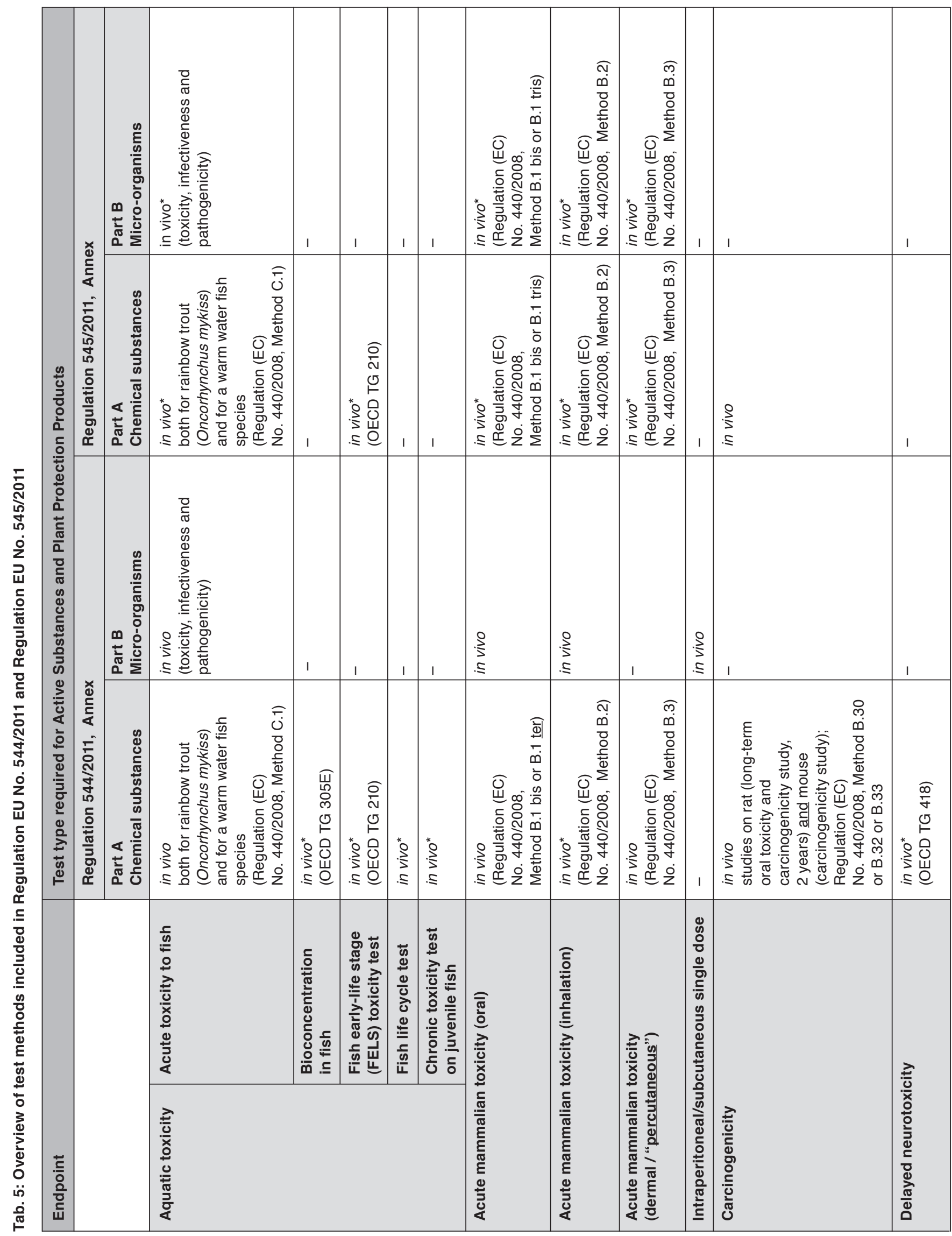




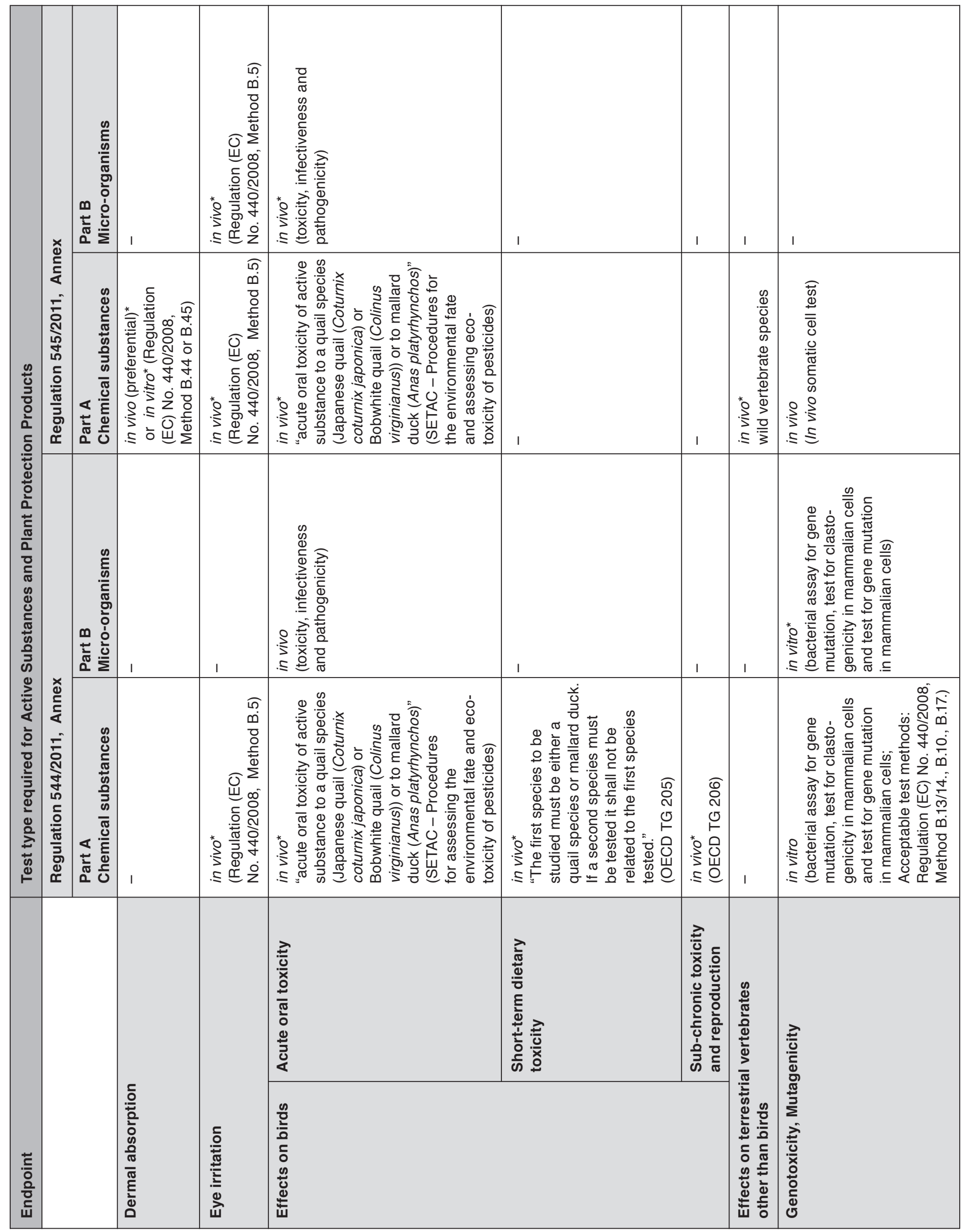




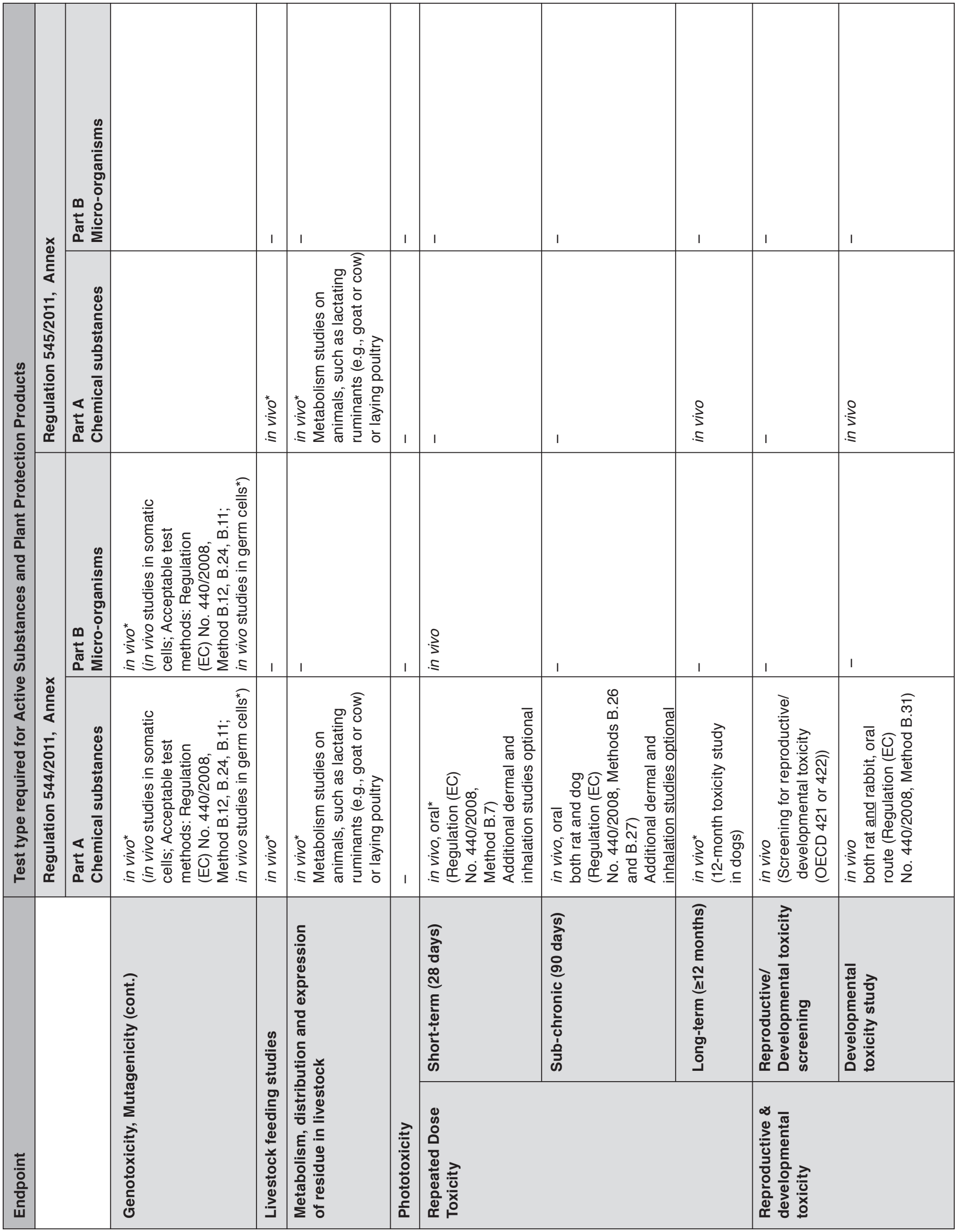




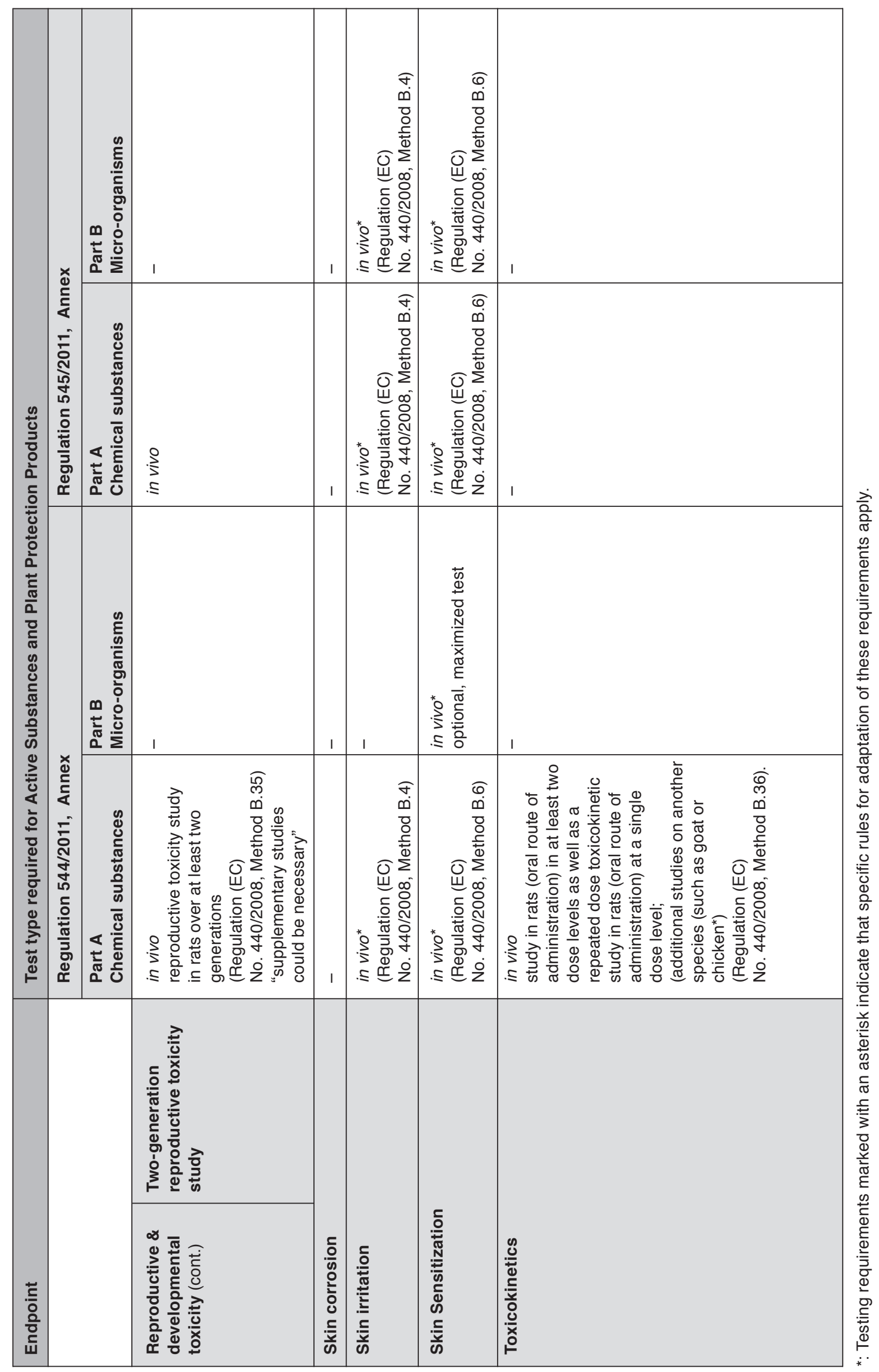


(EU) No. 545/2011 use the term "percutaneous." This is an inconsistency between the Regulations and may cause confusion for applicants.

The reference to the test method for acute oral toxicity is incorrect: PPPR data requirements refer to a method B.1 "ter" that does not exist; we conclude the reference is meant to be to method B.1 tris. Acute Oral Toxicity - Acute Toxic Class Method.

\subsubsection{Unnecessary requirement for 12-month toxicity testing on dogs}

Even though the other data requirements (REACH, BPR) call for testing on two species for sub-chronic toxicity (90 days), they do not specify the second species. In contrast, Regulation (EU) No. 544/2011 explicitly requires in Part A that for active substances (chemical substances) the non-rodent species of choice is the dog and that the sub-chronic oral toxicity (90 days) of an active substance to both rat and dog must always be reported. Furthermore, Regulation (EU) No. 544/2011 still requires that: "Where there is evidence that the dog is significantly more sensitive and where such data are likely to be of value in extrapolating results obtained to man, a 12-month toxicity study in dogs must be conducted and reported," even though there are several publications that question the added value of a 12-month-study on dogs because meta-analysis showed that there is no significant additional information obtained from a longer study (ECVAM, 2006; Kobel et al., 2010). In addition, the US Environmental Protection Agency (EPA) also indicated that the one-year chronic toxicity study in non-rodents does not necessarily need to be performed, and the sub-chronic 90-day study is considered sufficient ${ }^{32}$. Therefore, it is not in line with EU legislation on the protection of animals used for scientific purposes (Directive 2010/63/EU) to continue to require the 12-month-study.

\subsubsection{Lacking rules for adaptation of data requirements}

Although it is a common criterion to waive testing for aquatic toxicity if a substance is not expected to reach surface water following the proposed conditions of use, the PPPR nevertheless requires that results from tests on Acute Toxicity to fish have to be submitted for every active substance.

\subsubsection{Inconsistent design of Annexes}

While data requirements for micro-organisms for the PPPR shall be carried out in a tier-wise manner, this is not the case for chemical substances. It is not clear why these different approaches are followed.

\subsection{Novel Foods Regulation}

Since the revision of the Novel Foods Regulation came to a standstill on March 28, 2011 because of the failure to reach an agreement (see also 3.5), our analysis was limited to the current Regulation (EC) No. 258/97, as the COM Proposal $(\mathrm{COM}(2007) 872)$ is now no longer relevant. However, Regulation (EC) No. 258/97 does not include the data requirements for Novel Foods. In addition, there is no separate Regulation that lays down the data requirements for risk assessment of Novel Foods, but only the Commission Recommendation of July 29, 1997 (see also 3.5).

This Commission Recommendation addresses toxicological aspects in the "Key issues for the assessment of Novel Foods and Novel Food ingredients (NF)" in 3.7 (Toxicological requirements) and 3.10 (Allergenic potential) and in part XIII. Toxicological information on the NF but no explicit data requirements are defined that need to be assessed, and no standard testing methods are referred to. Rather, the assessment of several endpoints is recommended.

For example, the recommendation is given that: "If substantial equivalence to a traditional counterpart cannot be established, the safety assessment based on a case-by-case evaluation must consider the following elements: - consideration of the possible toxicity of the analytically identified individual chemical components, - toxicity studies in vitro and in vivo including mutagenicity studies, reproduction and teratogenicity studies as well as long term feeding studies, following a tiered approach on a case-by-case basis, - studies on potential allergenicity," and: "Most of the defined chemical substances can probably be tested for their safety similarly to food additives by utilizing conventional methods of safety evaluation as described in the SCF Report No 10. This implies the use of conventional toxicological testing procedures applied in a tiered sequence." Furthermore, "initial mutagenicity studies and an appropriate feeding study in a rodent species with an exhaustive investigation of all relevant toxicological parameters" are recommended to be considered as well. In addition, "additional investigations should be undertaken covering all the usual toxicological endpoints including metabolism, toxicokinetics, chronic toxicity/ carcinogenicity, reproductive function, teratogenicity, and possibly neurotoxicity and immunotoxicity" also should be considered, if data on structure or exposure point to it.

But, as mentioned above, no specific Test Guidelines or test method descriptions are referred to in this document. As cited, in vitro methods are referred to, and the recommendation is to design risk assessment in a tiered testing approach, which is a positive point. Apart from that, however, there is no document that lays down exactly which methods are required for risk assessment of Novel Foods, and as a result we also could not ascertain which, if any, available accepted alternative methods are considered for the risk assessment of Novel Foods.

At present, the approach followed in the current Novel Foods Regulation obviously is completely different from those followed for all other EU legislation we analyzed in terms of design, structure, and wording. It remains to be seen if and how a new revision of the Novel Foods Regulation is to be implemented.

32 US Federal Register (2007). Pesticides; Data Requirements for Conventional Chemicals, Technical Amendments, and Data

Requirements for Biochemical and Microbial Pesticides; Final Rules. EPA 40 CFR Parts 9, 152, 156, 159, et al. 


\section{Discussion}

The provisions of the Directive 2010/63/EU that require alternative methods to be used instead of animal tests wherever available are not fully implemented in data requirements of relevant EU legislation, which has been the subject of serious criticism (Schiffelers et al., 2007). Our study found this criticism to be legitimate. We analyzed data requirements of EU legislation dealing with chemicals, biocidal products, plant protection products, and Novel Foods. We identified several endpoints in these data requirements that still require testing on animals for risk assessment, even though accepted alternatives are available. Other endpoints lack reference to accepted alternative methods and/ or to measures to avoid animal testing and integrated testing strategies. The issues we identified were:

- Lack of procedure for inclusion of newly adopted OECD TGs in the TMR

- Lack of Adaptation to Technical Progress of the TMR:

- In Vitro Mammalian Cell Micronucleus Test (OECD TG 487), Acute Toxic Class Method for Acute Inhalation Toxicity (OECD TG 436), EOGRTS (OECD TG 443) and OECD GD No. 129 on using cytotoxicity tests to estimate starting doses for acute oral systemic toxicity tests not yet included in TMR

- Listing of outdated or unnecessary animal test methods for reproductive toxicity and skin sensitization (TMR)

- Lacking reference to corresponding OECD TGs in the TMR

- Issues concerning unclear, inconsistent or confusing structure of the TMR and its register of test methods

- Lacking reference to accepted alternative methods for skin irritation (BPR, PPPR)

- Lacking reference to accepted alternative methods for eye irritation (BPR, PPPR)

- Lacking reference to accepted alternative methods for skin sensitization (PPPR)

- Lacking reference to accepted alternative methods for reproductive toxicity (PPPR)

- Requirement of unnecessary 12-month toxicity study in dogs (PPPR)

- Inconsistencies in terminology, design of data requirements, and rules for adaptation to technical progress (PPPR)

- Introduction of endpoints that lack standard testing methods (respiratory sensitization, BPR)

All this may result in unnecessary or duplicated tests on animals that are performed to fulfill outdated or unclear data requirements and may cause confusion for competent authorities as well as for producers and applicants. There may be a multitude of reasons for data requirements not being adapted to technical progress or available accepted alternatives not being incorporated. These reasons may include differing views and a lack of trust in alternative methods (their safety, applicability, and/ or significance) on the part of competent authorities. Another reason may result from the tangle of competences, as several DGs of the EC are responsible for drafting proposals for relevant EU legislation, and thus for related data requirements as well. When these reasons are combined with a possible lack of communication between the different institutions, authorities, and other parties involved, the process becomes increasingly complicated and adaptation to technical progress becomes even more sluggish.

\subsection{Recommendations}

To reduce the number of animals used for testing in safety evaluations and at the same time ensure the best possible protection of humans, animals, and the environment, the EC should act immediately to eliminate from data requirements those animal tests that can be replaced by alternative methods.

Furthermore, revisions are needed in the design process of data requirements and how they are adapted to technical progress that will allow available alternative methods to be included in those data requirements and to be used immediately.

We found the data requirements in $\mathrm{REACH}$, and also the approach followed in this Regulation (extensive references and provisions to consider animal welfare and the promotion of alternative methods and the importance of minimizing testing on animals, general rules for adaptation of the data requirements), to be the most progressive and self-consistent of the EU legislation we analyzed. In addition, the upcoming BPR is largely based on REACH in terms of structure and wording of the data requirements. In contrast, the approaches followed in PPPR and Novel Foods Regulation differ significantly. We therefore strongly recommend that existing and future data requirements for all relevant EU legislations that require risk assessment of active substances or finished products, be it chemicals, biocidal products, plant protection products, Novel Foods or others, be uniformly designed and structured. This will help make them consistent and easier to comply with, and will harmonize the approaches and therefore also harmonize risk assessment. The approach could be based on the ideas and structures already implemented in REACH and the upcoming BPR to ensure consistency and to give users comprehensive advice on how to avoid and reduce animal testing, as well as advice on planning tiered testing strategies. This approach could also be used to extend the harmonization process to risk assessment of, e.g., pharmaceuticals, or nano-materials.

Risk assessment should always follow a consistent, stateof-the-art testing approach that includes all available accepted alternative methods and leaves room to adapt certain information requirements based on predetermined criteria (like waiving criteria, etc.). The testing approach should be designed so that it starts from non-testing approaches, e.g., evaluation of all available data on a substance and proceeding to computational methods like QSAR. It should then move to in vitro methods. Studies on vertebrate animals should be undertaken only as a last resort. The outcome of each step in the testing approach should be carefully considered to determine if the available data are sufficient or if it is necessary to proceed to the next step.

In addition, commonly accepted rules for adaptation of the data requirements should be included not only in the legislative text, e.g., in the form of a dedicated Annex, but also should be mentioned or referred to again in the data requirements themselves so that they will not be missed.

Ideally, the respective data requirements should not refer to or determine specific testing methods (like OECD TGs) or method 
descriptions but should be limited to list endpoints. The legally binding EU standardized test methods to determine the hazardous properties of chemicals are already centrally laid down in the TMR. We suggest, therefore, that all reference to test methods be limited to reference to the TMR. It may be easier to include all necessary testing methods in the TMR, especially since Adaptation to Technical Progress will surely be facilitated if there is only one Regulation that needs to be amended.

It might also promote consistency and harmonization if one central institution be made responsible for drafting and updating the data requirements. This institution, preferably, should also be in close contact with ECVAM and international bodies such as the OECD to ensure an unobstructed flow of information, expertise, and guidance on the availability and applicability of alternative methods. The respective DGs in charge of drafting new, or updating existing, EU legislation could work closely together and request the help of such an institution for drafting or updating the data requirements.

Harmonized and consistent rules should be established to determine how and in what time period newly accepted alternative methods should be updated/included in the data requirements. It is also necessary to lay down best practice rules for EU acceptance after adoption of an alternative method as an OECD TG, since currently there is no legally binding procedure. For example, criteria could be set down to decide if every alternative method adopted by the OECD has to be accepted in the EU as well. By these criteria it should also be possible to decide if an alternative method needs to be included/introduced into respective EU regulations. Rules also should be established that lay down how much time is acceptable for implementation.

Through harmonization in the design and structure of existing and future data requirements, together with a facilitated and frequent adaptation to technical progress, the number of animals used in regulatory toxicity testing could be significantly reduced in the EU. From an economic point of view, this approach would help simplify regulatory processes and reduce costs for both testing and administrative processes, in addition to limiting the numbers of animals and reducing the pain and suffering inflicted on them during testing.

\subsection{Outlook}

We will present a conclusion of our analysis of existing data requirements and our recommendations for a harmonized approach to the European Commission and related EU institutions. We hope to contribute to facilitating and harmonizing the process of drafting future data requirements for safety assessment of chemicals, active substances, and finished products. We hope also to encourage the EC to act immediately to eliminate those animal tests that can be replaced by alternative methods from the data requirements and to consider our suggestions for improvement. With our comprehensive analysis of EU legislation, we aim to contribute to consistency and state-of-the-art of the implementation of the $3 \mathrm{Rs}$ in this area and thus to the replacement and reduction of toxicity tests on animals.

\section{References}

Cooper, R. L., Lamb, J. C., Barlow, S. M., et al. (2006). A tiered approach to life stages testing for agricultural chemical safety assessment. Crit Rev Toxicol 36, 69-98.

ECVAM (2005). Executive summary (Eskes, C. and Zuang, V., eds.). Alternative (Non-Animal) Methods for Cosmetics Testing: Current Status and Future Prospects. Altern Lab Anim 33, Suppl 1, 7-18.

ECVAM (2006). ESAC Statement on Dog Toxicity Studies. http://ecvam.jrc.it/publication/ESAC25_statement_ DOG_20061207_C.pdf

Hartung, T. and Rovida, C. (2009). Chemical regulators have overreached. Nature 460, 1080-1081.

Kobel, W., Fegert, I., Billington, R., et al. (2010). A 1-year toxicity study in dogs is no longer a scientifically justifiable core data requirement for the safety assessment of pesticides. Crit Rev Toxicol 40, 1-15.

Kolar, R. (2006). Animal experimentation. Sci Eng Ethics 12, 111-122.

Nordberg, M., Duffus, J. H., and Templeton, M. (2004). Glossary of terms used in Toxicokinetics (IUPAC Recommendations 2003). Pure Appl Chem 76, 1033-1082.

OECD (1996). Test Guidelines Programme: Final Report on the OECD Workshop on Harmonisation of Validation and Acceptance Criteria for Alternative Toxicological Test Methods. Held in Solna, Sweden, 22-24 January 1996.

OECD (2005). Guidance document on the validation and international acceptance of new or updated test methods for hazard assessment. Series on Testing and Assessment 34, OECD, Paris.

OECD (2010). Guidance document on using cytotoxicity tests to estimate starting doses for acute oral systematic toxicity tests. Series on Testing and Assessment 129, OECD, Paris.

Russell, W. M. S. and Burch, R. L. (1959). The Principles of Humane Experimental Technique. London, UK: Methuen \& Co.

Schiffelers, M. J., Blaauboer, B. J., Fentener van Vlissingen, J. M., et al. (2007). Factors stimulating or obstructing the implementation of the $3 \mathrm{Rs}$ in the regulatory process. ALTEX 24 , 271-278

Worth, A. P. and Balls, M. (2001). The role of ECVAM in promoting the regulatory acceptance of alternative methods in the European Union. Altern Lab Anim 29, 525-535.

\section{Acknowledgements}

The authors wish to thank the German Foundation for the Promotion of Alternate and Complementary Methods to Reduce Animal Testing (SET) for funding this project. We would also like to thank Ulrike Gross for her assistance, helpful comments and advice on the text of this publication.

\section{Correspondence to}

Kristina Wagner

Spechtstr. 1

85579 Neubiberg

Germany 